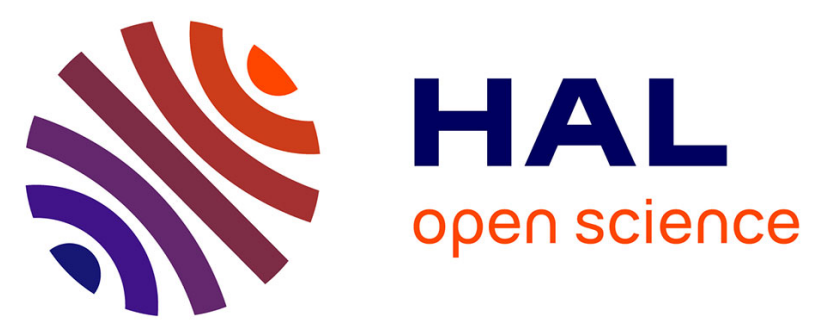

\title{
On crystallographic aspects of heterogeneous plastic flow during ductile tearing: 3D measurements and crystal plasticity simulations for AA7075-T651
}

Thilo F. Morgeneyer, Mikhail Khadyko, Ante Buljac, Lukas Helfen, François Hild, Ahmed Benallal, Tore Børvik, Odd Hopperstad

\section{To cite this version:}

Thilo F. Morgeneyer, Mikhail Khadyko, Ante Buljac, Lukas Helfen, François Hild, et al.. On crystallographic aspects of heterogeneous plastic flow during ductile tearing: 3D measurements and crystal plasticity simulations for AA7075-T651. International Journal of Plasticity, 2021, 144, pp.103028. 10.1016/j.ijplas.2021.103028 . hal-03250030

\section{HAL Id: hal-03250030 https://hal.science/hal-03250030}

Submitted on 23 Jun 2021

HAL is a multi-disciplinary open access archive for the deposit and dissemination of scientific research documents, whether they are published or not. The documents may come from teaching and research institutions in France or abroad, or from public or private research centers.
L'archive ouverte pluridisciplinaire HAL, est destinée au dépôt et à la diffusion de documents scientifiques de niveau recherche, publiés ou non, émanant des établissements d'enseignement et de recherche français ou étrangers, des laboratoires publics ou privés. 
T.F. Morgeneyer et al., International Journal of Plasticity, 144 (2021) 103028

\title{
On crystallographic aspects of heterogeneous plastic flow during ductile tearing: 3D measurements and crystal plasticity simulations for AA7075-T651
}

\author{
Thilo F. Morgeneyer ${ }^{\mathrm{a}, *}$, Mikhail Khadyko ${ }^{\mathrm{b}}$, Ante Buljac ${ }^{\mathrm{a}, \mathrm{c}}$, Lukas Helfen ${ }^{\mathrm{d}, \mathrm{e}}$, \\ François Hild ${ }^{c}$, Ahmed Benallal ${ }^{\mathrm{c}}$, Tore Børvik ${ }^{\mathrm{f}}$, Odd S. Hopperstad ${ }^{\mathrm{f}}$ \\ ${ }^{a}$ MINES ParisTech, PSL University, Centre des Matériaux, CNRS UMR 7633, BP 87, \\ 91003 Evry, France \\ ${ }^{b}$ UiT The Arctic University of Norway, Campus Narvik, Department of Building, Energy \\ and Material Technology, Lodve Langesgate 2, 8514 Narvik, Norway \\ ${ }^{c}$ Université Paris-Saclay, ENS Paris-Saclay, CNRS, LMT-Laboratoire de Mécanique et \\ Technologie, 91190 Gif-sur-Yvette, France \\ ${ }^{d}$ Institute for Photon Science and Synchrotron Radiation \\ Karlsruhe Institute of Technology (KIT), 76131 Karlsruhe, Germany \\ ${ }^{e}$ Institut Laue-Langevin, CS 20156, 38042 Grenoble Cedex 9, France

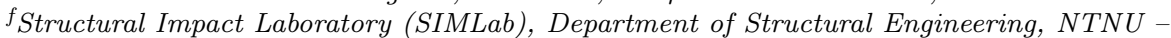 \\ Norwegian University of Science and Technology, 7491 Trondheim, Norway
}

\begin{abstract}
Crystallographic aspects of heterogeneous plastic flow during ductile tearing are assessed experimentally by combining in situ synchrotron laminography imaging of notched flat samples with a full-field measurement technique and numerical simulations with the crystal plasticity finite element method (CP-FEM). Advantage is taken of the plane strain condition in the region ahead of the notch root (i.e., in the plane normal to the crack propagation direction) to perform two-dimensional image correlation in the material bulk. Intermetallic particles provide image contrast that is registered during the correlation analyses. They reveal the early onset of slant strained bands along which the final slant crack propagated. Two-dimensional plane strain CP-FEM simulations using the grain shape and crystallographic orientations of the studied material show the same trends as those observed experimentally, namely, the appearance of early slant strained bands that cross tens of grains and that remain stable over the loading history. The ratio of the strains within and outside the bands is also similar to that observed experimentally.
\end{abstract}

Keywords: Heterogeneous plastic flow, plane strain, slant ductile fracture, synchrotron laminography, digital image correlation

\footnotetext{
${ }^{*}$ Corresponding author.

Email address: thilo.morgeneyer@mines-paristech.fr (Thilo F. Morgeneyer)
}

DOI: $10.1016 /$ j.ijplas.2021.103028 
T.F. Morgeneyer et al., International Journal of Plasticity, 144 (2021) 103028

\section{Introduction}

Whilst a considerable amount of research in recent decades has focused on damage and fracture at high levels of stress triaxiality within thick components with severe notches, it is only more recently (Bao and Wierzbicki, 2004 Pineau et al. 2016) that lower levels of stress triaxiality have been considered. This explains why less knowledge and fewer models are available to handle fracture at low levels of stress triaxiality (Pineau et al., 2016). Complex relationships between strain at fracture and stress triaxiality have been found at such levels (BaO and Wierzbicki, 2004). The definition and measurement of fracture strains in these circumstances are difficult due to the highly localised final failure process. Fracture at low stress triaxiality is relevant for formability and in-service failure predictions of thin walled components that are largely found in the transport industry. In forming limit diagrams, it has been identified that a plane strain state is particularly detrimental for the formability of sheets (Park et al. 2020 Tekkaya et al. 2020). The damage mechanisms at low levels of stress triaxiality are not fully understood (Torki and Benzerga, 2018).

In the past two decades, three-dimensional (3D) imaging techniques have allowed damage to be studied and to be quantified in situ (i.e., under mechanical load (Maire et al., 2001, Landron et al., 2012, Maire and Withers, 2014, Proudhon et al. (2020)). These techniques may help to better understand and predict the link between failure strain and stress triaxiality at low levels of stress triaxiality (Tancogne-Dejean et al. 2020). In addition, it is crucial to know more about the real local strain distribution and heterogeneity. Recent developments in 3D non-destructive imaging techniques and digital image correlation in both two-dimensional (Sutton, 2013) and three-dimensional problems (Bay et al. 1999: Bornert et al., 2004) have completely changed the landscape, and it has become possible to fill in this gap. It is now possible under certain circumstances (Morgeneyer et al. 2014) to completely follow three-dimensional crack propagation and experimentally measure relevant quantities such as strain and damage (Hild et al., 2015).

Recently, experiments were carried out on notched thin specimens to evaluate strain fields ahead of notches using a combination of in situ laminography and digital volume correlation (DVC) as a way of non-destructively studying damage and strain developments at the micrometre scale in sheet-like samples (Morgeneyer et al., 2014, 2016, Buljac et al., 2018). Synchrotron laminography allows regions of interest in plate-like samples to be imaged at micrometre resolution (Helfen et al., 2005). Using $1 \mathrm{~mm}$ thick recrystallised AA2198 T8 aluminium sheets that broke by slant fracture, early slant strained bands were observed to be the location of the final fracture (Morgeneyer et al., 2014). The studied material contained very little initial porosity (volume fraction $<0.03$ $\%$ ), and damage initiation at intermetallic particles and void growth from initial and nucleated voids were observed to occur only at later stages. The grains adopted pancake shapes in these rolled sheets. It was also shown that finite element calculations using either a von Mises plasticity model with relatively low hardening or a porous plasticity model (i.e., the Gurson-Tvergaard-Needleman

DOI: $10.1016 /$ j.ijplas.2021.103028 
T.F. Morgeneyer et al., International Journal of Plasticity, 144 (2021) 103028

(GTN) model) were not able to capture the early developed strained bands. For the same alloy under T3 conditions, despite increased work hardening which was expected to hamper localisation (Rudnicki and Rice, 1975), similar mechanisms were identified (Buljac et al., 2018) (i.e., stable slant strained bands as a precursor of the final slant crack). For an alloy containing initial porosity and smaller and more equiaxed grains (i.e., AA2139 T3 (Morgeneyer et al., 2016)), multiple parallel slant strained bands were measured in the fracture region. Their position was stable with respect to the underlying microstructure, but the activity was intermittent. Possible origins of intermittency were identified as high work hardening and Portevin-Le Chatelier (PLC) effect in this underaged condition (Ren et al. 2019$)$. In all these alloys, the strain level inside the slant strained bands was approximately twice the strain outside before final localisation.

Other important contributions worth highlighting are those of Hahn and Rosenfield (Hahn and Rosenfield, 1965) and Rosenfield et al. (Rosenfield et al., 1966). The authors studied locally yielding zones on large notched and thin specimens fabricated from $3 \%$ silicon steel. The specimens contained centrally located edge slots and were fabricated from a thick plate. Their surfaces were electro-polished and etched to reveal the plastic zone and then re-ground to various depths, polished, and re-etched to delineate the plastic zone in various interior sections. For edge-slotted silicon steel specimens, local yielding was observed to be predominantly of the plane-strain plastic-hinge type until the extent of the yielded zone was equal to approximately the sheet thickness. Further deformation, under plane-stress conditions, proceeded with a $45^{\circ}$ shear mode.

The behaviour of some alloys at the macroscale may be predicted by isotropic plasticity models (Morgeneyer et al., 2014). These models homogenise the inherently heterogeneous plastic response of crystalline grains. Yet, heterogeneous flow in the form of slant bands ahead of a notch was successfully reproduced (Rousselier et al. 2017) by accounting for PLC effect. The strained bands remained mobile in these simulations. The alloy considered in the present study does not exhibit PLC effects.

At the microscale, the plastic behaviour of polycrystalline materials is heterogeneous and anisotropic due to the variation in crystallographic orientation between grains. The so-called crystal plasticity finite element method (CP-FEM) can be used to model various characteristic features of microscale deformations in polycrystals, such as deformation accommodation by grains, strain concentrations and shear bands. In such studies, electron back-scattered diffraction (EBSD) is typically used to measure the crystal orientation distribution on the surface of specimens. These data are used to reconstruct the microstructure of polycrystals (i.e., grain morphology and orientation) in a finite element model. The specimen may subsequently be subjected to mechanical load, during which the strain fields in the polycrystal can be measured with high-resolution digital image correlation (Bretheau et al. 2003, Sutton et al., 2007; Guery et al., 2014). The test is simulated with the established finite element model, and the simulated strains are directly compared to the strains measured in the experiment.

A number of studies have followed the methodology outlined above, in-

DOI: $10.1016 /$ j.ijplas.2021.103028 
cluding (Sachtleber et al., 2002, Saai et al., 2010, Badulescu et al., 2011; Zhu et al., 2011 Pinna et al. 2015) for polycrystals of aluminium alloys and for other types of polycrystalline materials (Lim et al., 2014, 2016, Kapoor et al. 2018). Some more recent studies include Lin et al. (2020), who investigated $\mathrm{Cu}$ polycrystals, Ganesan et al. (2020) who modelled a $\mathrm{Mg}$ alloy, and (Demir and Gutierrez-Urrutia, 2020), who studied deformation in Al olygocrystals. The level of correspondence between experimentally measured strains and those obtained by simulations vary from very high (Lim et al., 2014) to somewhat lower in most other studies. In all the studies mentioned above, the good qualitative reproduction of the polycrystal behaviour may be noted. The sources of errors and discrepancies between finite element models and experimental data have been analysed in several works. The effect of reproducing realistic 3D structures instead of a 2D structure based on only the surface EBSD measurements was analysed for tensile and compression tests, the role of realistic boundary conditions was studied (Heripre et al., 2007, Zhang et al., 2015, St-Pierre et al. 2008), and the effect of material parameters of the single-crystal plasticity model was investigated (Zhang et al. 2015; Khadyko et al., 2018). In addition, the localised behaviour in the CP-FEM model was shown to be affected by the grain boundary compatibility effects (Taupin et al., 2016) and by dynamic strain ageing (Gupta et al. 2019).

The objective of the paper is twofold: i) to repeat the experimental study reported by Morgeneyer et al. (2014) but for the high-strength AA7075-T651 aluminium alloy, and ii) to apply CP-FEM simulations in an attempt to reproduce the main experimental observations and thus overcome the deficiencies of macroscopic models. Advantage is taken from the plane strain conditions that were observed both in numerical simulations (Bron and Besson, 2006) and in experiments via DVC measurements (Buljac et al., 2018, 2016). This observation allows a projection-based correlation technique to be used in the analysis of such experiments and reduction of the computational time of CP-FEM simulations by considering $2 \mathrm{D}$ models. It is found that the experimental observations of early slant strained bands in AA7075-T651 are predicted by the CP-FEM simulations.

\section{Material}

The aluminium alloy AA7075 was delivered as a 20-mm thick rolled plate. The plate was in T651 temper, which means that the material had been stressrelieved by slight stretching and subsequently artificially aged to achieve peak hardness condition. The nominal chemical composition was given by Fourmeau et al. (2015).

Figure 1 shows the Cauchy stress versus logarithmic strain response up to fracture for the material tested in the rolling $(\mathrm{L}), 45^{\circ}$ and long transverse $(\mathrm{T})$ directions. The strains at necking inception are indicated by crosses in the curves. The values beyond necking inception were obtained by laser measurement and do not account for structural effects induced by the neck. The stress-strain

DOI: $10.1016 /$ j.ijplas.2021.103028 
T.F. Morgeneyer et al., International Journal of Plasticity, 144 (2021) 103028

curves show the anisotropy of the material with respect to strength and failure strain. The highest stress levels are achieved for loading in the rolling and transverse directions, while the stress level is significantly lower when loading in the $45^{\circ}$ direction. The failure strain is markedly larger in the $45^{\circ}$ direction than in the other two directions. The average Lankford coefficients in the rolling $(\mathrm{L})$, $45^{\circ}$ and long transverse $(\mathrm{T})$ directions were estimated to be $0.64,1.25$ and 0.82 , respectively, displaying anisotropy in plastic flow (Fourmeau et al., 2013).

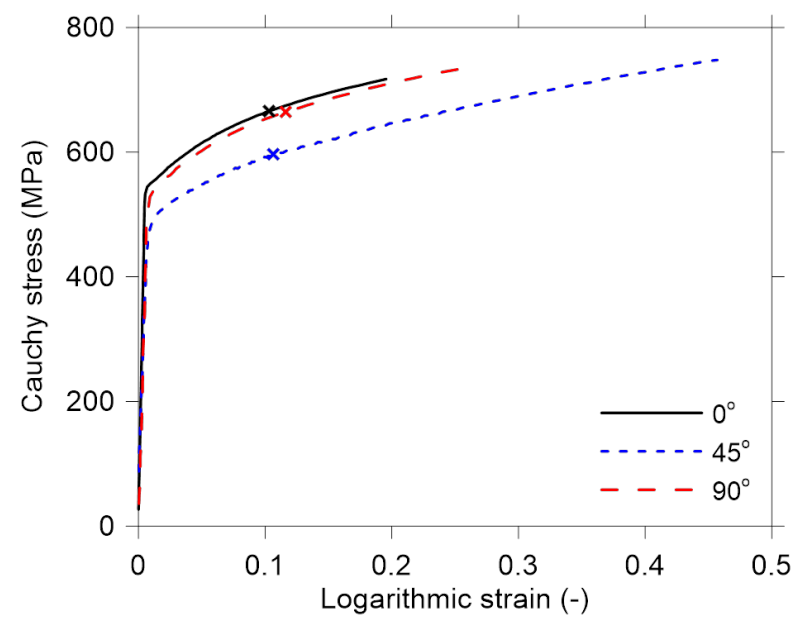

Figure 1: Cauchy stress vs. logarithmic strain curves for tensile tests along the $0^{\circ}(\mathrm{L}), 45^{\circ}$ and $90^{\circ}(\mathrm{T})$ directions up to fracture. The crosses mark the logarithmic strains at necking inception. Adapted after Fourmeau et al. (2011).

The non-recrystallised microstructure of the material is illustrated in Figure 2. Owing to the rolling process, the material has flat and elongated grains of average size with a standard deviation equal to $91 \pm 31 \mu \mathrm{m}$ along the rolling direction (L), $41 \pm 15 \mu \mathrm{m}$ along the long transverse direction $(\mathrm{T})$ and $13 \pm 5 \mu \mathrm{m}$ along the short transverse (or thickness) direction (S) based on measurements of grain maps in the three principal planes of the plate 11 As reported by Fourmeau et al. (2015), the grains consist of sub-grains that are separated by low-angle boundaries.

\footnotetext{
${ }^{1}$ Note that the rolling direction, the long transverse direction and the short transverse direction were denoted RD, TD and ND, respectively, by Fourmeau et al. (2015 2011) and by Pedersen et al. (2011).
}

DOI: $10.1016 /$ j.ijplas.2021.103028 


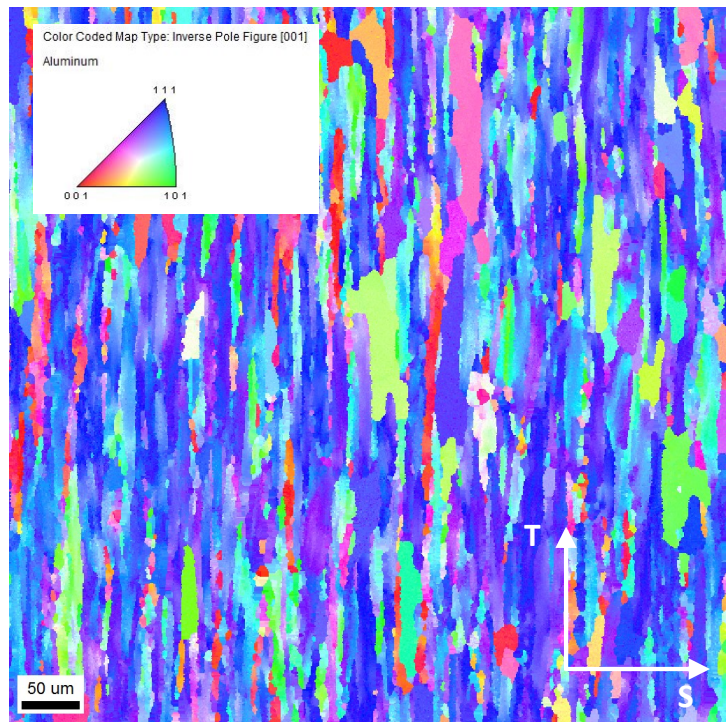

Figure 2: Grain map obtained by EBSD from the selected AA7075-T651 plate, where T (TD) and $\mathrm{S}(\mathrm{ND})$ are aligned with the long and short transverse directions, respectively. Adapted after Fourmeau et al. (2015).

The orientation distribution function (ODF) obtained for the AA7075-T651 plate by electron back-scattered diffraction (EBSD) is shown in Figure 3 . The material has a strong deformation texture that is responsible for marked plastic anisotropy in yield stress (Figure 1) and plastic flow (Fourmeau et al., 2011). In the peak hardness condition, the alloy contains nano-sized hardening precipitates, dispersoids and constituent particles (Fourmeau et al. 2015). The large constituent particles were broken up during the rolling process and aligned in stringers along $\mathrm{L}$ in the rolling plane (Pedersen et al., 2011). More details about the microstructure and the stress-strain behaviour of the alloy used in the present study can be found in Fourmeau et al. (2015, 2011) and by Pedersen et al. (2011).

DOI: $10.1016 /$ j.ijplas.2021.103028 


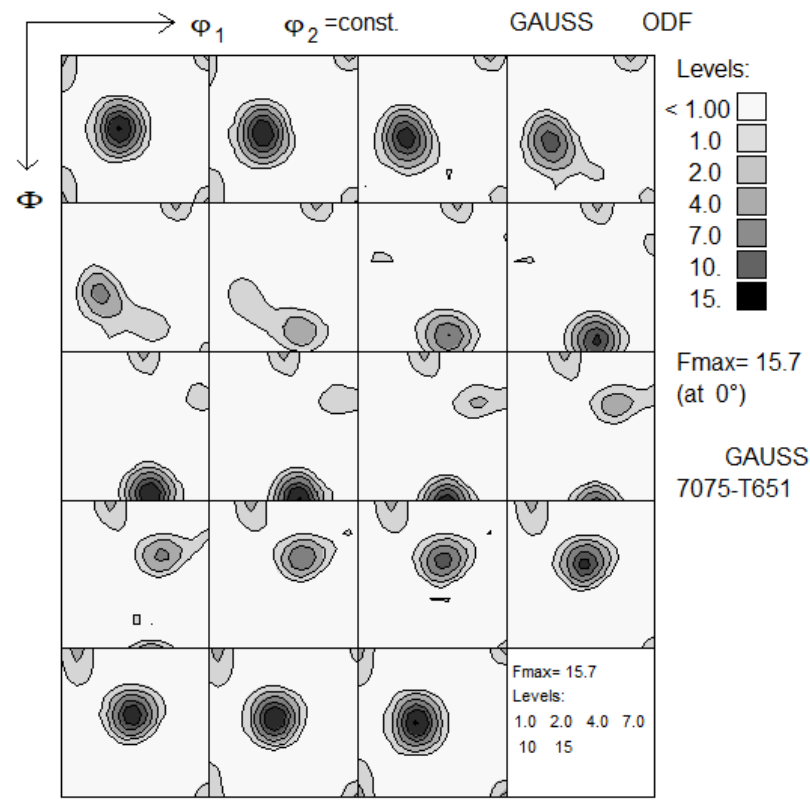

Figure 3: Orientation distribution function of the studied AA7075-T651 plate material. Adapted after (Fourmeau et al. 2015).

\section{Experiment}

\subsection{Experimental setup and specimen}

The mechanical test was performed using a 1-mm thick flat and notched specimen (1) as shown in Figure 4(b). The specimen was made by electrical discharge machining (EDM) and the geometry is defined in Figure 4(a). This geometry is similar to those used by Buljac et al. (2018, 2016), but pinholes were machined into the sample to apply step-wise monotonic loading with an electromechanical actuator equipped with a load cell (3) (Figure 4(b)). The in situ machine was mounted onto the turntable of the laminography rotation stage (4). An anti-buckling device (2) was used to prevent the sample from significant buckling and large out-of-plane motions. Loading was applied in the long transverse direction $(\mathrm{T})$, and crack propagation occurred in the rolling direction (L) of the tested alloy. A digital microscope (5) was mounted onto a translation stage to acquire optical images at every load step for subsequent digital image correlation (DIC) analyses. It consisted of a Basler ACA204025GM camera combined with a Mitutoyo VMU-V microscope with a 2x objective lens. A typical image for measuring the crack tip opening displacement, $\delta_{5}$ (Zerbst et al. 2009), is given in Figure 4(c).

DOI: $10.1016 /$ j.ijplas.2021.103028 


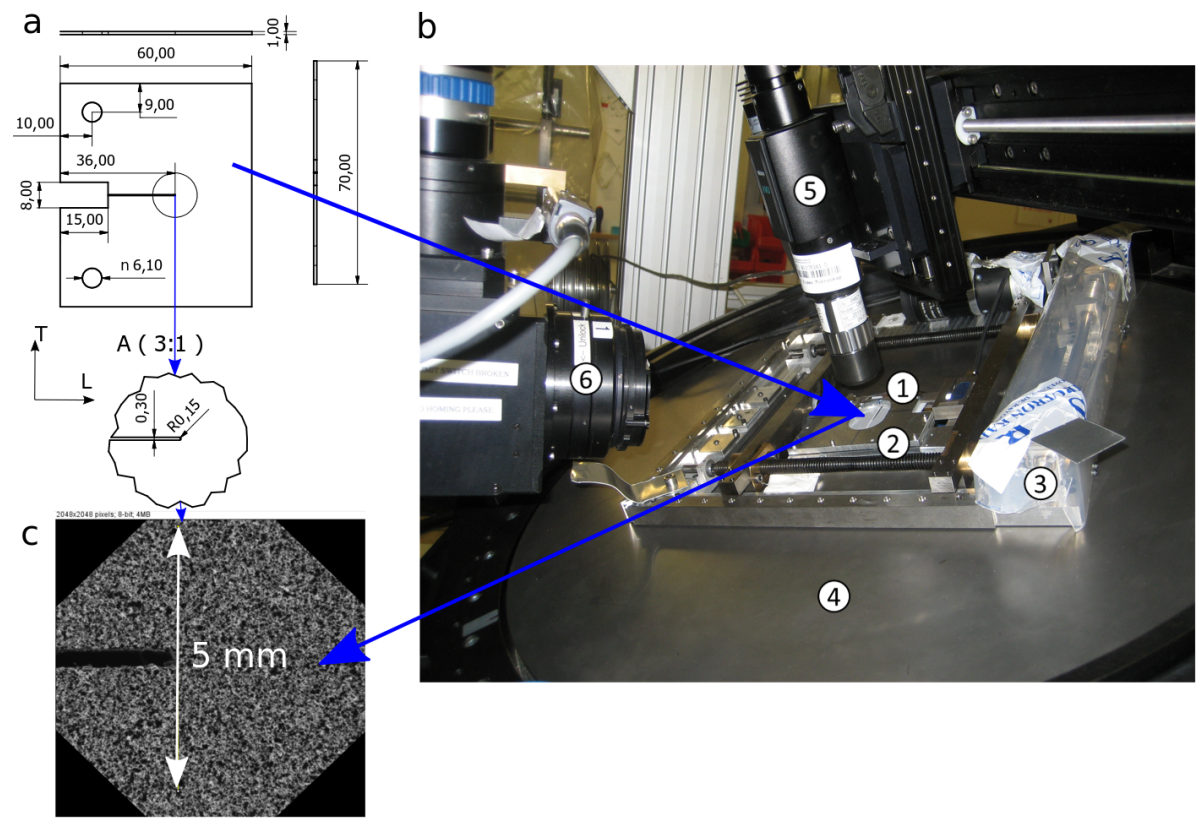

Figure 4: (a) Sample geometry (in $\mathrm{mm}$ ) with the notch aligned along the rolling direction (L) and the load applied through pinholes in the long transverse direction (T). (b) Sample (1) with the anti-buckling device, (2) mounted in the in situ loading machine, (3) on the laminography rotation stage (4), and the X-ray detector 6). (c) Surface image obtained by the optical microscope for DIC analyses (5).

The force vs. cross-head displacement curve is presented in Figure 5(a) and shows the global response of the CT-like specimen. In every scan (circles), a small load drop was observed due to some weak relaxation phenomena. The global response curve started with an initial linear region followed by a nonlinear part. Finally, unstable crack propagation took place, which may be linked to the low tearing modulus of the AA7075-T651 aluminium alloy and the low stiffness of the in situ loading device. During unstable pop-in failure, the crack propagated with no or limited applied cross-head displacement (Petit et al. 2018). More local displacement measurements were obtained using optical images and optical extensometers. The force vs. crack tip opening displacement (CTOD), $\delta_{5}$, up to the maximum load is reported in Figure 5(b). This very local measurement shows a monotonically increasing notch opening that was successfully applied by the dedicated loading device. The CTOD value after failure is not reported because out-of-plane motions prevented a sharp image to be acquired.

DOI: $10.1016 /$ j.ijplas.2021.103028 

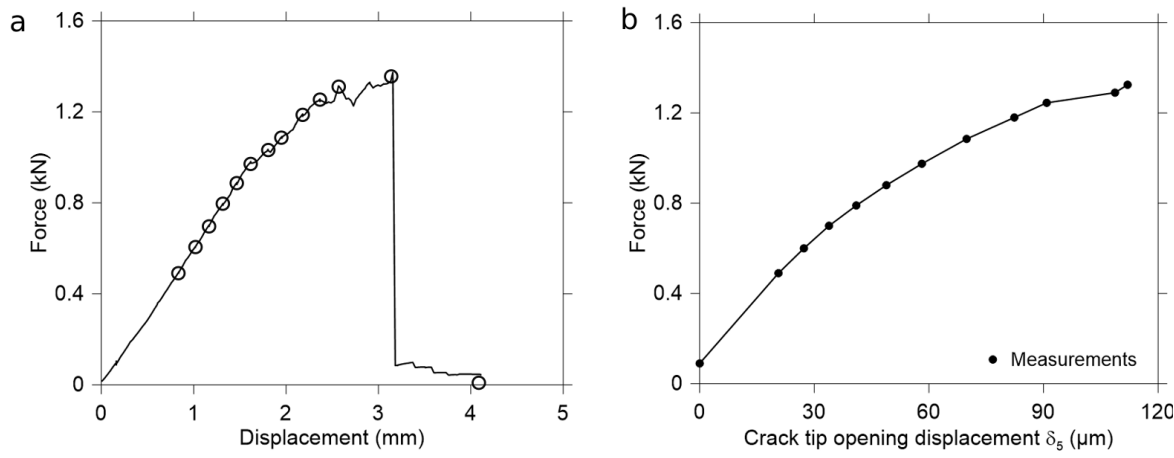

Figure 5: (a) Force vs. cross-head displacement curve for the CT-like specimen. The circles indicate scans. (b) Force vs. crack tip opening displacement, $\delta_{5}$, obtained by means of an optical extensometer.

\subsection{Synchrotron laminography}

The experiment was performed at the ID19 beamline of the European Synchrotron Radiation Facility (ESRF, Grenoble, France). The laminography rotation axis was inclined with respect to the X-ray beam direction by an angle $\theta \approx 65^{\circ}$. A pink beam with an X-ray energy of approximately $26 \mathrm{keV}$ allowed for a good compromise between penetration and depth resolution. The series of 3,599 60 ms radiographs was then processed to reconstruct 3D volumes by using a filtered back-projection algorithm (Myagotin et al., 2013). Parameter optimisation was performed automatically using a GPU-accelerated implementation (Vogelgesang et al., 2016). The notch root was selected as the region for the laminographic scan. The reconstructed volumes were represented by discrete grey level fields (8-bit digitisation). They had a size of $2,560 \times 2,560 \times 2,300$ voxels. The physical size (length) of one cubic voxel was equal to $0.65 \mu \mathrm{m}$. Each voxel inside the reconstructed volume contained the grey level determined by the local linear attenuation coefficient of X-rays. In the present case, image contrast was mainly due to heavy intermetallic particles of micrometre size.

\subsection{Projection correlation}

For the selected AA7075 alloy, image contrast in the reconstructed 3D images (mainly provided by intermetallic particles) was low (Figure 6(a-b)), and it was difficult to reliably perform DVC measurements.

DOI: $10.1016 /$ j.ijplas.2021.103028 


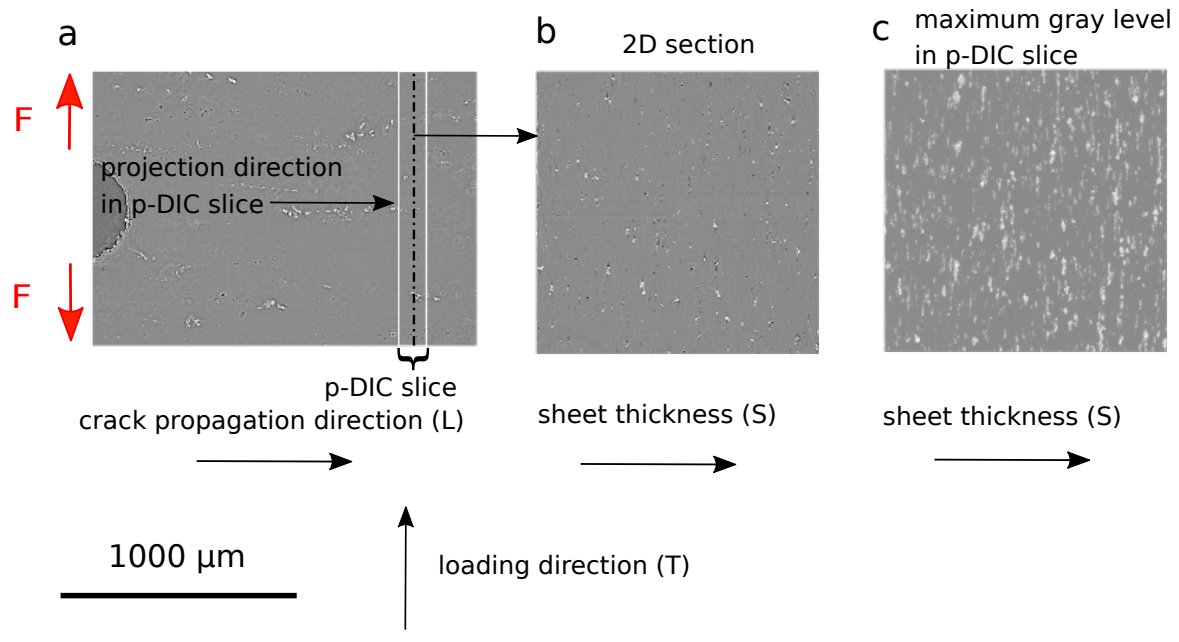

Figure 6: Illustration of data generation for projection DIC. Laminography data at $490 \mathrm{~N}$ : (a) T-L section, (b) T-S section in the centre of the p-DIC slice, and (c) 2D projection of the maximum grey levels found in the 150 voxel thick (p-DIC) slice.

For this reason, contrast was increased by projecting the maximum grey levels (white) found in a stack of 150 slices (i.e., normal to the crack propagation direction and positioned in the plane strain region) onto a single 2D section (Figure 6(c)). In other words, contrast provided by intermetallic (white) particles and aluminium matrix (grey) in a $100 \mu \mathrm{m}$ thick slice was projected onto a $2 \mathrm{D}$ image and subsequently used for the $2 \mathrm{D}$ registrations. This approach was deemed valid since in front of the notch root (starting at a distance of approximately $250 \mu \mathrm{m}$ from the notch root) of such CT-like samples, plane strain conditions were observed both in numerical simulations (Bron and Besson, 2006) and experimentally via DVC measurements (Buljac et al., 2018, 2016). The zero strain condition corresponds to the crack propagation direction (L). The $2 \mathrm{D}$ section onto which the maximum grey levels were projected was located $1010 \mu \mathrm{m}$ ahead of the notch root.

The previous steps were the main elements of the so-called projection DIC procedure employed in this work. The main benefits with respect to DVC (at the expense of depth resolution) were significantly faster registration procedures and, in the present case, the ability to measure the kinematics in the plane strain region ahead of the notch root. In Roth et al. (2018), projection DIC was performed for steel that did not contain sufficient contrast to perform DVC. The consistency of projection DIC with corresponding DVC measurements was shown in a previous study (see Figure 4 in Buljac et al. (2018)).

Finite element DIC was used with an unstructured mesh composed of triangular elements with an edge size of 24 pixels and a regularisation length of 60 pixels (Tomicevic et al. 2013). The reference configuration of the present registrations was the scan acquired at $490 \mathrm{~N}$. Scans at lower load levels were blurred due to spurious rigid body motions during scanning.

DOI: $10.1016 /$ j.ijplas.2021.103028 
T.F. Morgeneyer et al., International Journal of Plasticity, 144 (2021) 103028

\section{Single crystal plasticity model}

The single crystal plasticity model used in the finite element simulations of the experiment is described below. A rate-dependent formulation valid for small elastic strains but finite rotations and finite plastic strains was adopted. A more detailed description of the applied model can be found in Dumoulin et al. (2009). The multiplicative decomposition of the deformation gradient $\mathbf{F}$ into elastic and plastic parts was employed

$$
\mathbf{F}=\mathbf{F}^{e} \cdot \mathbf{F}^{p}
$$

where $\mathbf{F}^{e}$ describes elastic deformations and rigid-body rotations and $\mathbf{F}^{p}$ the deformation of the material by plastic slip on a number of systems. Owing to plastic incompressibility, $\operatorname{det} \mathbf{F}^{p}=1$, and thus $\operatorname{det} \mathbf{F}^{e}=\operatorname{det} \mathbf{F}>0$. As the elastic strains were assumed to be small, the hyperelastic relationship was defined by the Saint Venant-Kirchhoff model

$$
\overline{\mathbf{S}}=\overline{\mathbb{C}}: \overline{\mathbf{E}}^{e}
$$

where $\overline{\mathbf{S}}$ is the second Piola-Kirchhoff stress tensor, $\overline{\mathbb{C}}$ the fourth-order elasticity tensor, and $\overline{\mathbf{E}}^{e}$ the elastic Green-Lagrange strain tensor. The stress and elastic strain tensors are defined by

$$
\overline{\mathbf{S}}=\left(\operatorname{det} \mathbf{F}^{e}\right)\left(\mathbf{F}^{e}\right)^{-1} \cdot \boldsymbol{\sigma} \cdot\left(\mathbf{F}^{e}\right)^{-T}
$$

and

$$
\overline{\mathbf{E}}^{e}=\frac{1}{2}\left(\left(\mathbf{F}^{e}\right)^{T} \cdot \mathbf{F}^{e}-\mathbf{I}\right)
$$

where $\boldsymbol{\sigma}$ is the Cauchy stress tensor, and $\mathbf{I}$ the second-order identity tensor. Assuming orthotropic symmetry, the non-zero components of the elasticity tensor $\overline{\mathbb{C}}$ are $c_{11}, c_{12}$ and $c_{44}$, where Voigt notation was used (Dumoulin et al., 2009).

The plastic flow rule reads

$$
\dot{\mathbf{F}}^{p} \cdot\left(\mathbf{F}^{p}\right)^{-1}=\sum_{\alpha=1}^{N_{s}} \dot{\gamma}^{\alpha} \mathbf{S}_{0}^{\alpha}
$$

where $\mathbf{S}_{0}^{\alpha}=\mathbf{m}_{0}^{\alpha} \otimes \mathbf{n}_{0}^{\alpha}$ is Schmid's tensor, and $\mathbf{m}_{0}^{\alpha}$ and $\mathbf{n}_{0}^{\alpha}$ are unit vectors defining the slip direction and the slip plane normal of the slip system $\alpha$, respectively. $N_{s}$ gives the number of slip systems, which is equal to 12 for FCC materials, including the investigated $\mathrm{Al}$ alloy. The slip rate $\dot{\gamma}^{\alpha}$ is described by a viscoplastic constitutive relationship

$$
\dot{\gamma}^{\alpha}=\dot{\gamma}_{0}\left(\frac{\left|\tau^{\alpha}\right|}{\tau_{c}^{\alpha}}\right)^{\frac{1}{m}} \operatorname{sign}\left(\tau^{\alpha}\right)
$$

where $\dot{\gamma}_{0}$ is a reference shear rate and $m$ is the strain rate sensitivity parameter. The resolved shear stress $\tau^{\alpha}$ on the slip system $\alpha$ is calculated as

$$
\tau^{\alpha}=\left(\overline{\mathbf{C}}^{\mathbf{e}} \cdot \overline{\mathbf{S}}\right): \mathbf{S}_{0}^{\alpha}
$$

DOI: $10.1016 /$ j.ijplas.2021.103028 
T.F. Morgeneyer et al., International Journal of Plasticity, 144 (2021) 103028

where $\overline{\mathbf{C}}^{e}=\left(\mathbf{F}^{e}\right)^{T} \cdot \mathbf{F}^{e}$ is the elastic right Cauchy-Green deformation tensor.

The critical resolved shear stress $\tau_{c}^{\alpha}$ on slip system $\alpha$ is defined by the hardening rule

$$
\dot{\tau}_{c}^{\alpha}=\theta(\Gamma) \sum_{\beta=1}^{N_{s}} q_{\alpha \beta}\left|\dot{\gamma}^{\beta}\right|
$$

where $q_{\alpha \beta}=q+(1-q) \delta_{\alpha \beta}$ is the matrix describing the latent hardening of the single crystal, $q$ the ratio of the latent hardening rate to the self hardening rate, and $\delta_{\alpha \beta}$ the Kronecker delta (i.e., $\delta_{\alpha \beta}$ equals unity if $\alpha=\beta$ and zero otherwise). The hardening modulus $\theta(\Gamma)$, or the self-hardening rate, is given by

$$
\theta(\Gamma)=\theta_{\tau} \exp \left(-C_{\tau} \Gamma\right)
$$

where $\theta_{\tau}$ and $C_{\tau}$ are material parameters and the cumulated slip $\Gamma$ is given by the growth law

$$
\dot{\Gamma}=\sum_{\alpha=1}^{N_{s}}\left|\dot{\gamma}^{\alpha}\right|
$$

The initial critical resolved shear stress $\tau_{0}$ was assumed to be the same for all slip systems. The single-crystal plasticity model was implemented in Fortran as a user-material subroutine using an explicit time integration scheme Grujicic and Batchu, 2002).

\section{Finite element model}

The plane strain deformation of the material in front of the notch root was modelled with a 2D plane strain finite element (FE) model. The EBSD data were used directly to construct the microstructure (i.e., grain shapes and crystallographic orientations). The EBSD scan was performed on a $620 \times 620$ grid with $1 \mu \mathrm{m}$ steps. Each grid point produced three Euler angles, corresponding to the orientation of the crystal at the point in the global coordinate system defined by the rolling $(\mathrm{L})$, transverse $(\mathrm{T})$ and short transverse $(\mathrm{S})$ directions. To represent these data, an FE model with $620 \times 620$ elements was created, and each element was assigned the orientation of the corresponding grid point in the EBSD scan. The EBSD measurements always contain some noise due to uncertainties in the measurements and the material itself, as well as points where indexing failed. The EBSD data were prepared using the texture processing software MTEX (Mainprice et al. 2011) to mitigate noise and deal with "bad pixels." The FE mesh with the contour plot of the first Euler angle obtained with MTEX is shown in Figure 7 to illustrate the final result. The modelled area was thus a square with $620 \mu \mathrm{m}$ sides, which is comparable to the size of the area analysed with DIC (i.e., a square with approximately $1000 \mu \mathrm{m}$ sides).

DOI: $10.1016 /$ j.ijplas.2021.103028 


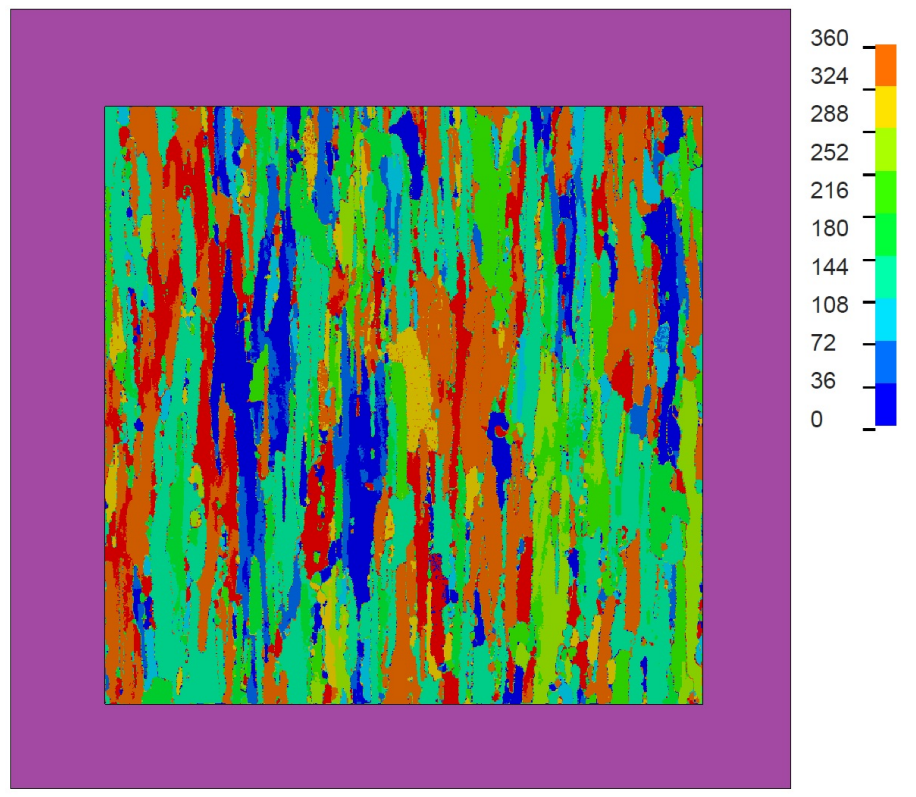

Figure 7: 2D plane strain FE model with the first Euler angle in degrees plotted in each element modelled with crystal plasticity, whereas the elements modelled with von Mises plasticity are shown in purple. The plot is oriented such that the long transverse $(\mathrm{T})$ direction is vertical and the short transverse $(\mathrm{S})$ direction is horizontal. von Mises plasticity was assumed in the purple box to relax the effect of Dirichlet boundary conditions.

The FE model of the polycrystal thus consisted of 384,400 four-node plane strain quadrilateral elements with reduced integration and Flanagan-Belytschko stiffness-based hourglass control (Flanagan and Belytschko, 1981) arranged in a structured mesh. In addition, the polycrystal was surrounded by a layer of elements with von Mises plasticity (see purple box in Figure 7). The material parameters of these elements describe the global stress-strain curve of the AA7075-T651 alloy. This approach provides more relaxed boundary conditions than fixed or planar edges and are deemed more appropriate for the actual problem than periodic boundary conditions. To simulate plane strain tension along the transverse $(\mathrm{T})$ direction of the plate, the velocity, which was smoothly ramped up to a constant value, was applied to the top edge of the FE model, while the bottom edge was clamped in the transverse direction. Top and bottom edges were free to move in the short transverse $(\mathrm{S})$ direction, the left and right edges were defined as free surfaces.

The hardening parameters of the single crystal plasticity model were obtained by fitting the stress-strain curve from simulations with a simplified CPFEM model to the experimental stress-strain curve of AA7075-T651 (Fourmeau et al. 2015) obtained in the uniaxial tension test in the $0^{\circ}$ material direction (Figure 1). The simplified CP-FEM model was a representative volume element (RVE) containing 1,000 cubic elements, each representing a single grain. The representative set of 1,000 orientations for this model was constructed from

DOI: $10.1016 /$ j.ijplas.2021.103028 
T.F. Morgeneyer et al., International Journal of Plasticity, 144 (2021) 103028

EBSD data representing the crystallographic texture of the rolled plate. LSOPT (Stander et al., 2008) was used to fit the hardening parameters to the experimental data. A detailed description of the simplified CP-FEM model and fitting procedure can be found in Khadyko et al. (2015). The values of the elastic parameters, the rate sensitivity parameter, the reference slip rate and the latent hardening constant, which are assumed to be common to $\mathrm{Al}$ alloys, were taken from the literature (Khadyko et al. 2015). The material parameters are listed in Table 1.

Table 1: Material parameters of the CP-FEM model.

\begin{tabular}{|c|c|c|c|c|}
\hline$c_{11}(\mathrm{MPa})$ & $c_{12}(\mathrm{MPa})$ & $c_{44}(\mathrm{MPa})$ & $\dot{\gamma}_{0}\left(\mathrm{~s}^{-1}\right)$ & $m(-)$ \\
\hline 106,430 & 60,350 & 28,210 & 0.01 & 0.005 \\
\hline$q(-)$ & $\tau_{0}(\mathrm{MPa})$ & $\theta_{\tau}(\mathrm{MPa})$ & $C_{\tau}(-)$ & \\
\hline 1.4 & 200.0 & 38.8 & 0.243 & \\
\hline
\end{tabular}

The rate sensitive formulation of the $\mathrm{CP}$ model with a small value of the rate sensitivity parameter $m$ used in this study should produce results similar to rate independent model (Mánik and Holmedal, 2014).

It should be noted that the material parameters were obtained by simulating a uniaxial tension test with 3D brick elements and then used in a simulation of plane-strain tension with 2D quadrilateral elements. In principle, the material parameters should be independent of the way they were obtained. However, previous studies showed that the parameters may be affected by the type of test and simulation used for calibration purposes. Uniaxial tension and plane-strain tension tests were used to calibrate the $\mathrm{CP}$ model for the same material, and the calibrated parameters were somewhat different (Khadyko et al., 2016, 2017). However, the difference was not large enough to affect the work-hardening and localisation behaviour of such alloys, at least in a qualitative sense.

The behaviour of the elements along the boundary of the FE model was described by von Mises plasticity, where the flow stress $\sigma_{f}$ was defined in terms of the equivalent plastic strain $p$ by $\sigma_{f}=\sigma_{0}+Q(1-\exp (-C p))$. The parameters $\sigma_{0}=540 \mathrm{MPa}, Q=177 \mathrm{MPa}$ and $C=12.6$ were obtained by least squares fit of the same experimental stress-strain curve (Fourmeau et al. 2015) that was used to determine the parameters of the single crystal plasticity model.

The simulations were performed with the FE code LS-DYNA (Hallquist et al. 2006) using explicit time integration of the momentum equations, and mass scaling was applied to reduce the computation time. To ensure that the simulation was quasi-static, the kinetic energy was maintained at a small percentage of the internal energy throughout the deformation process.

DOI: 10.1016/j.ijplas.2021.103028 
T.F. Morgeneyer et al., International Journal of Plasticity, 144 (2021) 103028

\section{Results}

\subsection{Experimental analysis}

Figure 8 shows some results of the laminography investigation in terms of 2D sections normal to the thickness direction at the mid-thickness of the plate for different load levels. The EDM-machined notch is shown on the left side of the sections. The notch opening is observed for the different load levels. Iron-containing intermetallic particles appear in white, the aluminium matrix in grey, $\mathrm{Mg}_{2} \mathrm{Si}$ particles (Lugo et al., 2011) in dark grey, and pores in black. Some intermetallic particles contained cracks prior to plastic deformation. Other particles failed at the 790-N load step when located near the notch. This fracture event was likely to be brittle and governed by reaching high maximum principal stresses. At the load level 1,290 N, a crack initiated. This crack was linked to the notch surface through a shear crack (Buljac et al., 2018). The final crack propagation regime was unstable and only partially included the intermetallic particles seen in this section, thereby highlighting the 3D nature of the fracture process. Other clusters of detrimental particles could not be seen in the selected section.

DOI: $10.1016 /$ j.ijplas.2021.103028 


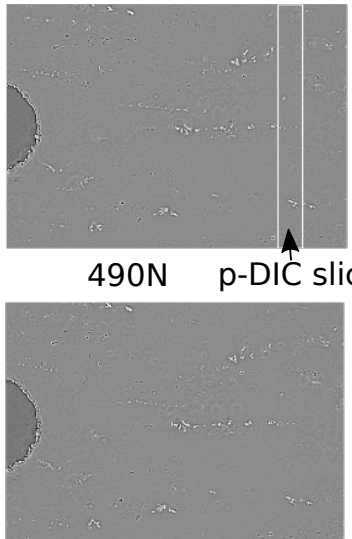

$790 N$

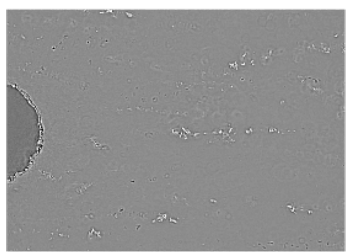

$1030 \mathrm{~N}$

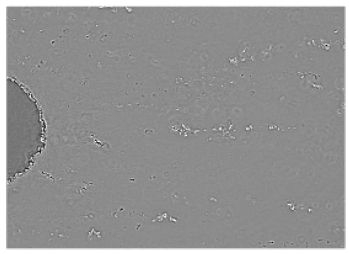

$1245 N$

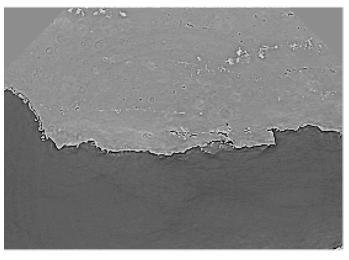

Fracture

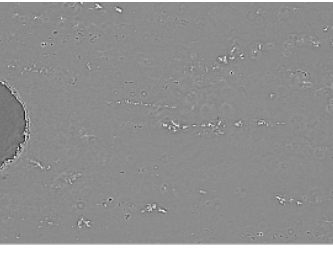

$600 \mathrm{~N}$

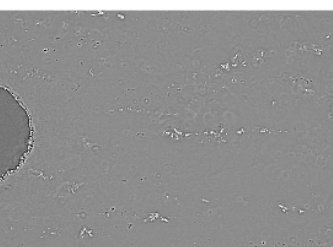

$880 \mathrm{~N}$

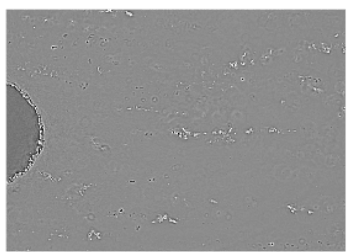

$1085 N$

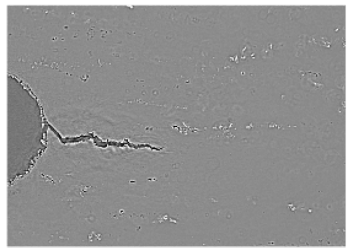

$1290 N$

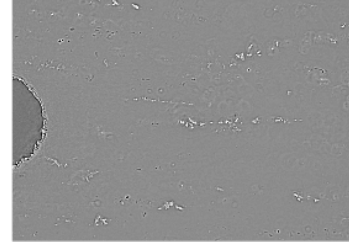

$700 N$

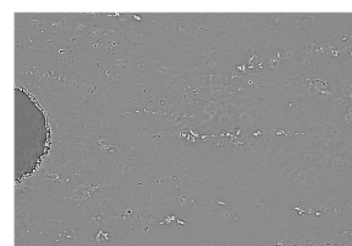

$975 N$

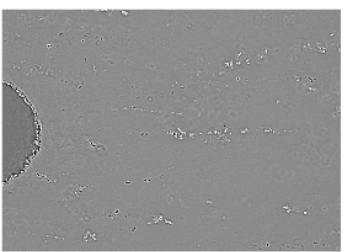

$1180 N$

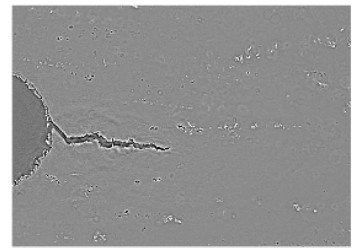

$1325 \mathrm{~N}$

$1000 \mu \mathrm{m}$

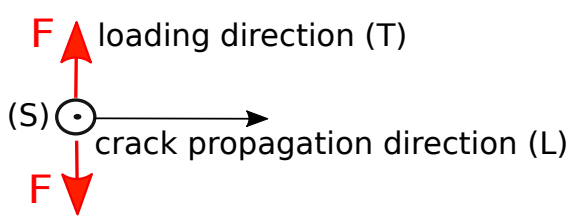

Figure 8: 2D sections of the reconstructed laminography data. The sections are in the sheet plane, i.e., normal to the thickness direction and at mid-thickness height. The corresponding force levels are indicated.

Figure 9 shows 2D sections normal to the crack propagation direction $1 \mathrm{~mm}$ ahead of the notch root. The strain field was measured at this location. As shown in previous works (Buljac et al., 2018; Bron and Besson, 2006; Buljac et al., 2016), a plane strain condition prevailed normal to the crack propagation 
T.F. Morgeneyer et al., International Journal of Plasticity, 144 (2021) 103028

direction. This is the reason why particles seen in this section (i.e., in the centre of the p-DIC slice) remained the same over the entire loading history. Very little damage accumulation was observed at the micrometre scale prior to final fracture. Consistent with the macroscopic force displacement curve (Figure 5), the final crack propagation was unstable. It resulted in a slant crack in the given section. This slant crack did not follow a single plane but there was a step at approximately mid-thickness. The plane strain condition allowed 2D-DIC to be performed on projected laminography data (i.e., projection DIC).

DOI: $10.1016 /$ j.ijplas.2021.103028 


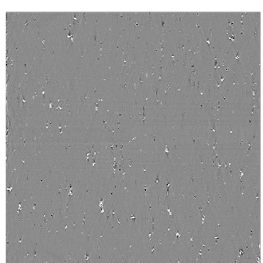

$490 \mathrm{~N}$

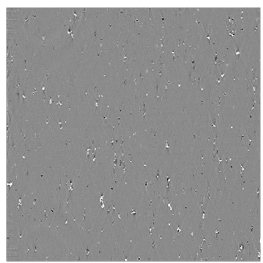

$790 \mathrm{~N}$

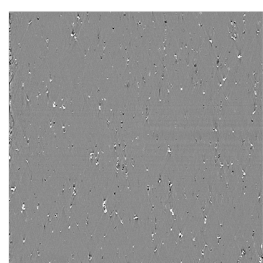

$1030 \mathrm{~N}$

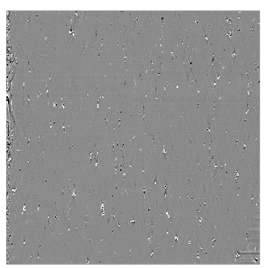

$1245 N$

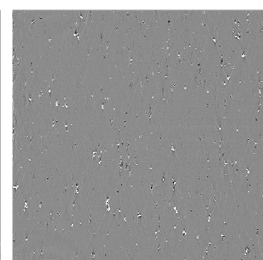

$600 \mathrm{~N}$

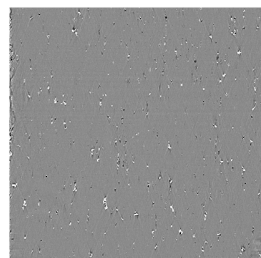

$880 \mathrm{~N}$

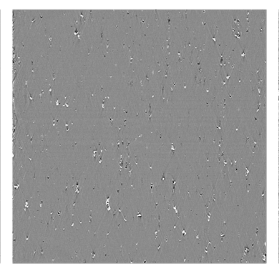

$1085 N$

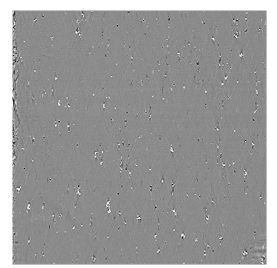

$1290 \mathrm{~N}$

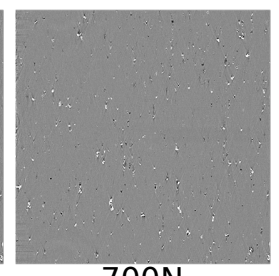

$700 \mathrm{~N}$

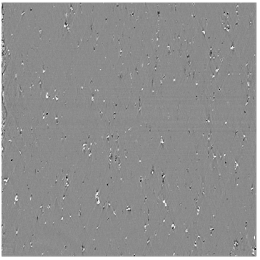

$975 N$

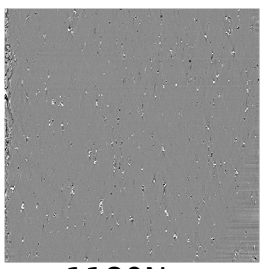

$1180 \mathrm{~N}$

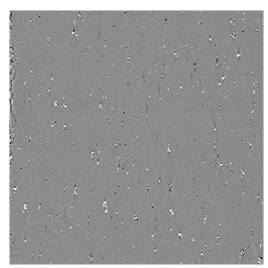

$1325 \mathrm{~N}$

F

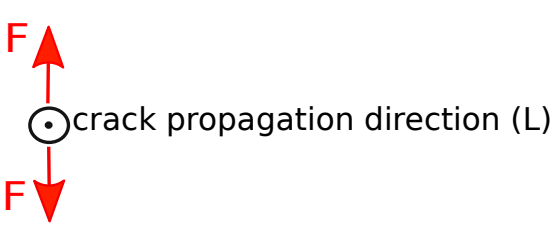

Figure 9: 2D sections of reconstructed laminography data. The sections are normal to the crack propagation and $1 \mathrm{~mm}$ ahead of the notch root. The corresponding force levels are indicated.

The 2D images resulting from the projection of maximum grey levels are shown in Figure 10. Their contrast is mainly caused by iron-rich intermetallic particles. The projection height was $100 \mu \mathrm{m}$ in the crack propagation direction. Figure 8 shows for the 490-N load step the position of the region of interest (ROI) for projection DIC. This load step corresponds to the reference configuration.

DOI: $10.1016 /$ j.ijplas.2021.103028 


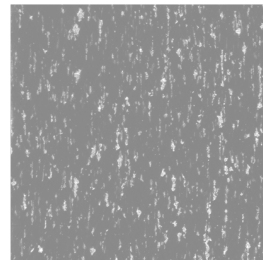

$490 \mathrm{~N}$

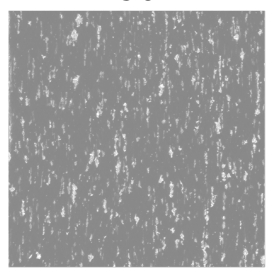

$790 N$

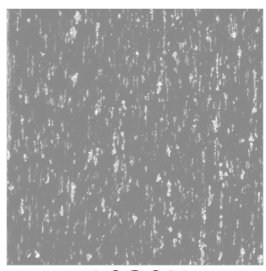

$1030 \mathrm{~N}$

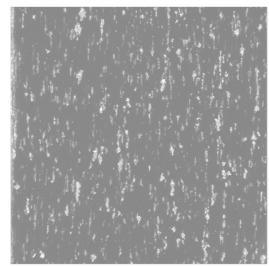

$1245 N$

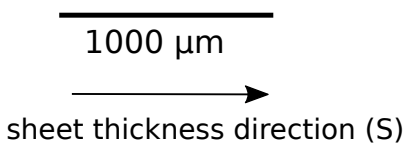

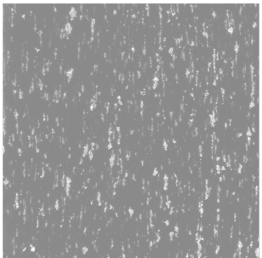

$600 \mathrm{~N}$

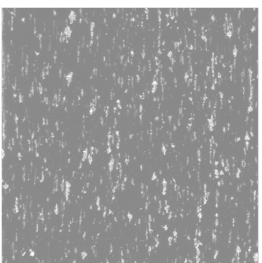

$880 \mathrm{~N}$

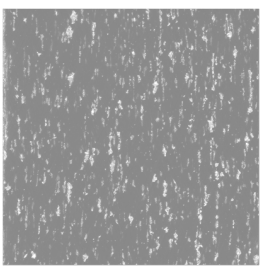

$1085 \mathrm{~N}$

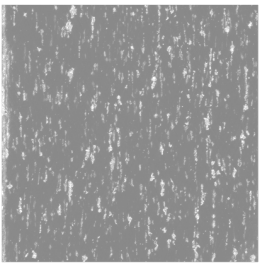

$1290 N$

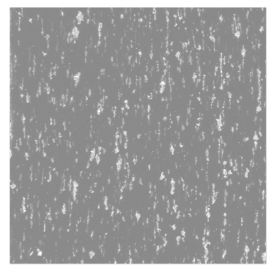

$700 \mathrm{~N}$

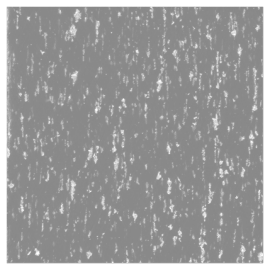

$975 \mathrm{~N}$

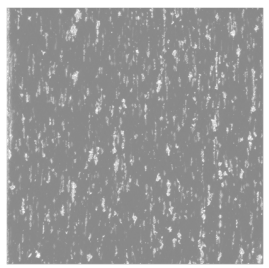

$1180 \mathrm{~N}$

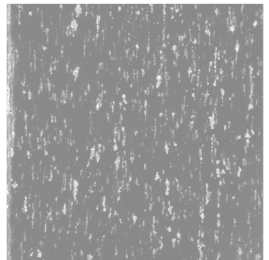

$1325 N$

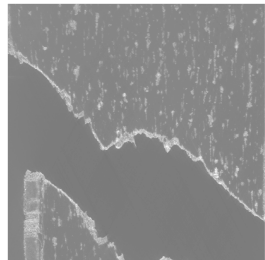

Fracture

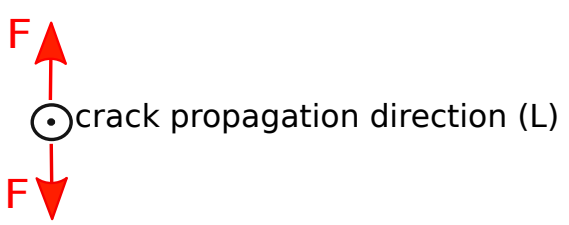

Figure 10: Projections of maximum grey levels in the $100 \mu \mathrm{m}$ thick volume onto a $2 \mathrm{D}$ plane along the crack propagation direction (L). The location was $1010 \mu \mathrm{m}$ from the notch.

The conjecture of plane strain conditions in the crack propagation direction was substantiated by the observation that it was always the same particles that gave rise to the observed contrast (i.e., there was no out-of-plane motion). Further, there was no evidence of damage nucleation in the projected images until final fracture. At the load level $1,325 \mathrm{~N}$, the left side of the specimen surface is seen as the specimen width decreases due to thickness contraction.

Projection DIC fields of the Green-Lagrange strain $E_{x x}$ in the loading direc-

DOI: 10.1016/j.ijplas.2021.103028 
T.F. Morgeneyer et al., International Journal of Plasticity, 144 (2021) 103028

tion $\mathrm{T}$ are plotted in Figure 11 for all load steps, where the $x$-, $y$ - and $z$-axes of the Cartesian coordinate system are aligned with the T, L and S directions, respectively. The fields are laid over the initial projection. The first two load steps show strain levels less than 0.01, and the fluctuations are an indication of measurement uncertainties. The signal-to-noise ratio during these measurements was too low to draw meaningful conclusions (Buljac et al., 2018).

The first load step for which a non-uniform strain field could be detected was $975 \mathrm{~N}$. Several slant bands appeared, with one band crossing the entire section from the top left to the bottom right. There were also two parallel long bands crossing the entire section from the bottom left to the top right. The ratio between the strains inside and outside these bands was at the order of 2. The measured maximum total strain in the loading direction was only 0.03 for this load step. For the subsequent load steps, the levels of total strain kept increasing, and the previously described strained bands remained stable in space and became increasingly more pronounced.

Above the load level $1180 \mathrm{~N}$, the deformation mostly developed in the strained bands, approaching a strain localisation situation. Just before fracture, the strain levels rose up to 0.12 . Final fracture occurred along one of the previously measured bands (i.e., the one from the upper left to the lower right corners). For this last step, the strain field could be successfully measured only for the upper part of the sample. In the center of the sample, the crack did not follow the slant strained band but took a different path. It should be noted, however, that the point at which there was a step in the crack path corresponded to the intersection of previously measured orthogonal slant bands.

DOI: $10.1016 /$ j.ijplas.2021.103028 


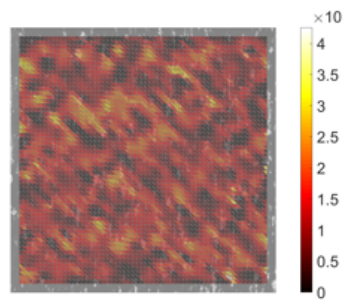

$490 N-600 N$

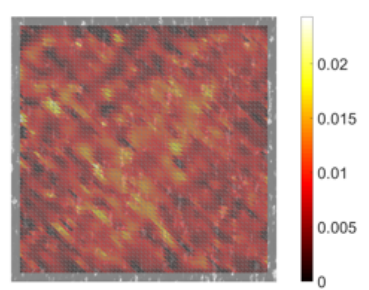

$490 N-880 N$

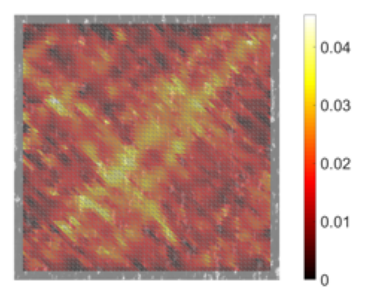

$490 N-1085 N$

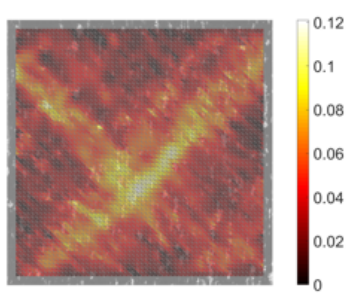

$490 N-1290 N$

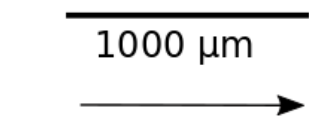

sheet thickness direction (S)

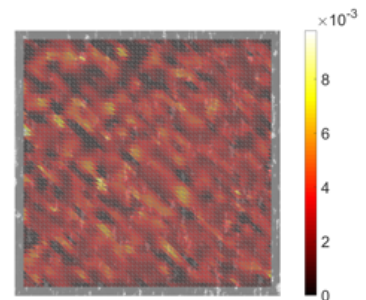

$490 N-700 N$

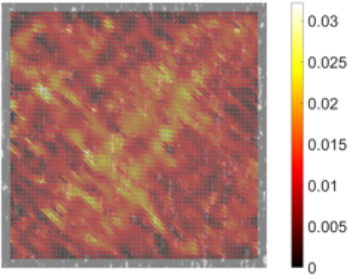

$490 N-975 N$

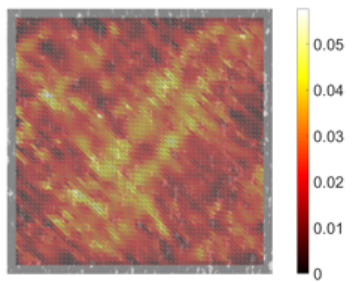

$490 N-1180 N$

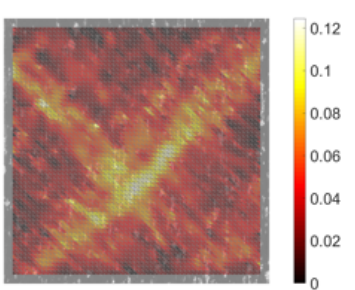

$490 N-1325 N$

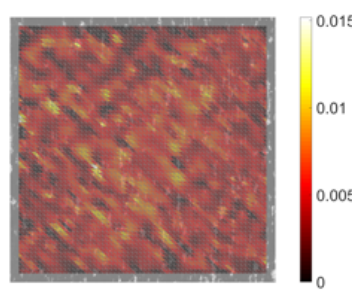

$490 N-790 N$

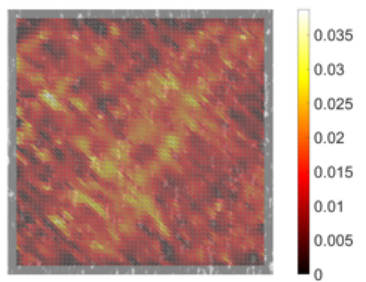

$490 N-1030 N$

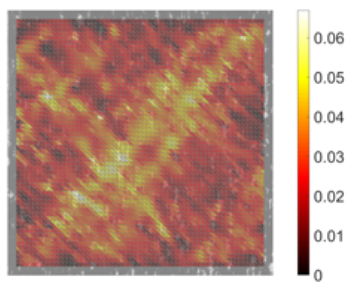

$490 N-1245 N$

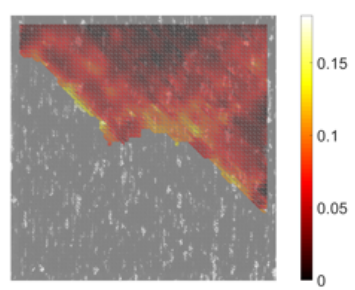

490N-Fracture

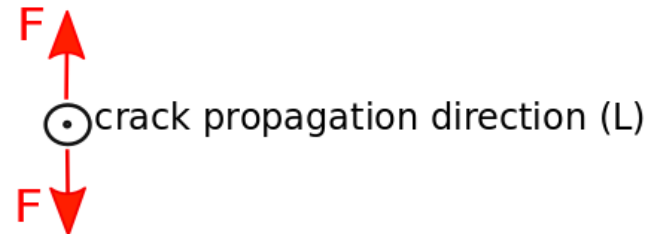

Figure 11: Projection DIC results. Fields of Green-Lagrange strain $E_{x x}$ in the vertical loading direction for different load increments. The studied section is normal to the crack propagation direction, $1 \mathrm{~mm}$ ahead of the notch root. The reference configuration corresponds to the (elastic) state at $490 \mathrm{~N}$.

DOI: $10.1016 /$ j.ijplas.2021.103028 
T.F. Morgeneyer et al., International Journal of Plasticity, 144 (2021) 103028

Figure 12(a) shows the location of a slant line along which the GreenLagrange strain $E_{x x}$ was assessed. The orientation of the slice is the same as in Figure 11. In Figure 12(b), the strain profiles along the line are plotted and found to be heterogeneous for all load steps, where $\zeta$ is the coordinate along the slant line. There are two strain maxima in the centre of the line that remained the highest over the entire loading history and along which the final crack propagated. Other local maxima were also found in other locations along the line. The ratio between the strain in the two main maxima and the average strain in the surrounding region was approximately 2 at the beginning. At the last two load levels (i.e., $1290 \mathrm{~N}$ and $1325 \mathrm{~N}$ ), the strains became more concentrated in the two main bands with a ratio of approximately 2.5-3 between the strains inside and outside the bands. The last correlation was performed from the loaded state at $490 \mathrm{~N}$ to a state after failure of the sample. Only half of the strain profile was accessible, as only half the sample was imaged (see Figure 8). The highest strain was measured in the band that led to failure. Some strain increase during this last step was also found for the adjacent band. The material outside these bands showed less accumulated strain than in the previous step. This may be due to the fact that elastic unloading took place, as the fractured sample was scanned in the unloaded state. The final load step may be identified as a strain localisation situation, where all strains concentrated into a localised region of the sample.
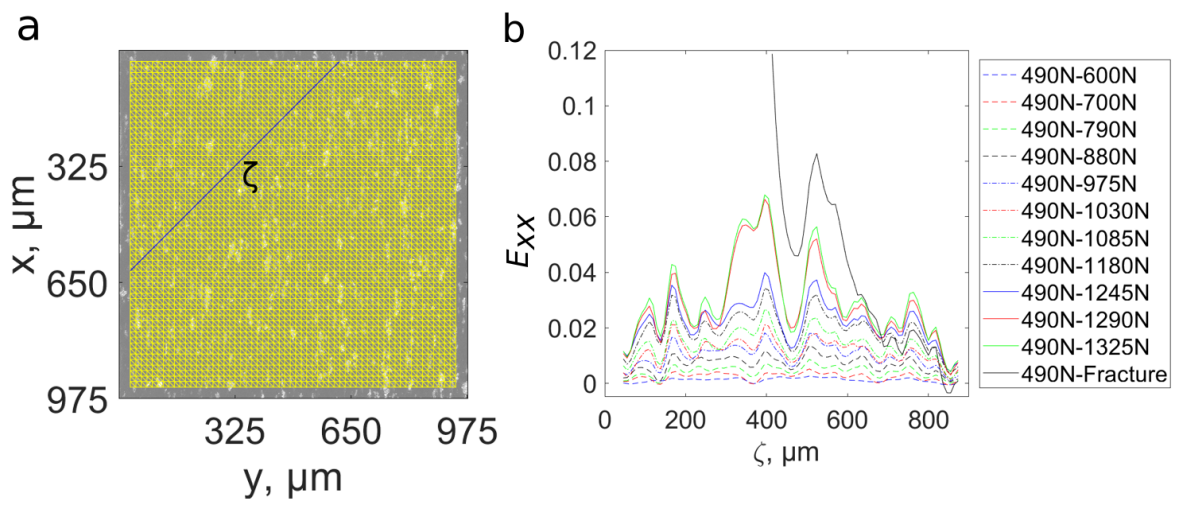

Figure 12: (a) Position of the line along which the projection DIC strain profile was investigated. (b) Measured profiles of the Green-Lagrange strain $E_{x x}$ in the vertical loading direction along the line for all load steps.

\subsection{Numerical results}

Fields of the equivalent von Mises plastic strain are plotted on the deformed mesh in Figure 13 for different levels of global Green-Lagrange strain $E_{x x}^{G}$ in the loading direction. The selected strain levels correspond approximately to those in the experiment and to the strain at which global shear bands formed in the simulation. The elements modelled with von Mises plasticity are not reported. The strain field evolution is typical for aluminium alloys with high yield stress

DOI: $10.1016 /$ j.ijplas.2021.103028 
T.F. Morgeneyer et al., International Journal of Plasticity, 144 (2021) 103028

and low work hardening (Khadyko et al. 2016). In the initial transient stage of the simulation, plastic deformation in different parts of the model did not show any fixed pattern, and both spatial and temporal heterogeneities were observed. At an average strain of approximately $2 \%$, a pattern of higher and lower plastic strains developed and remained more or less permanent until global shear band formation occurred at an average strain of approximately $20 \%$, at which point almost all the deformation concentrated in the bands. In the experiment, the fracture occurred much earlier, so the same process could not be observed.

DOI: $10.1016 /$ j.ijplas.2021.103028 

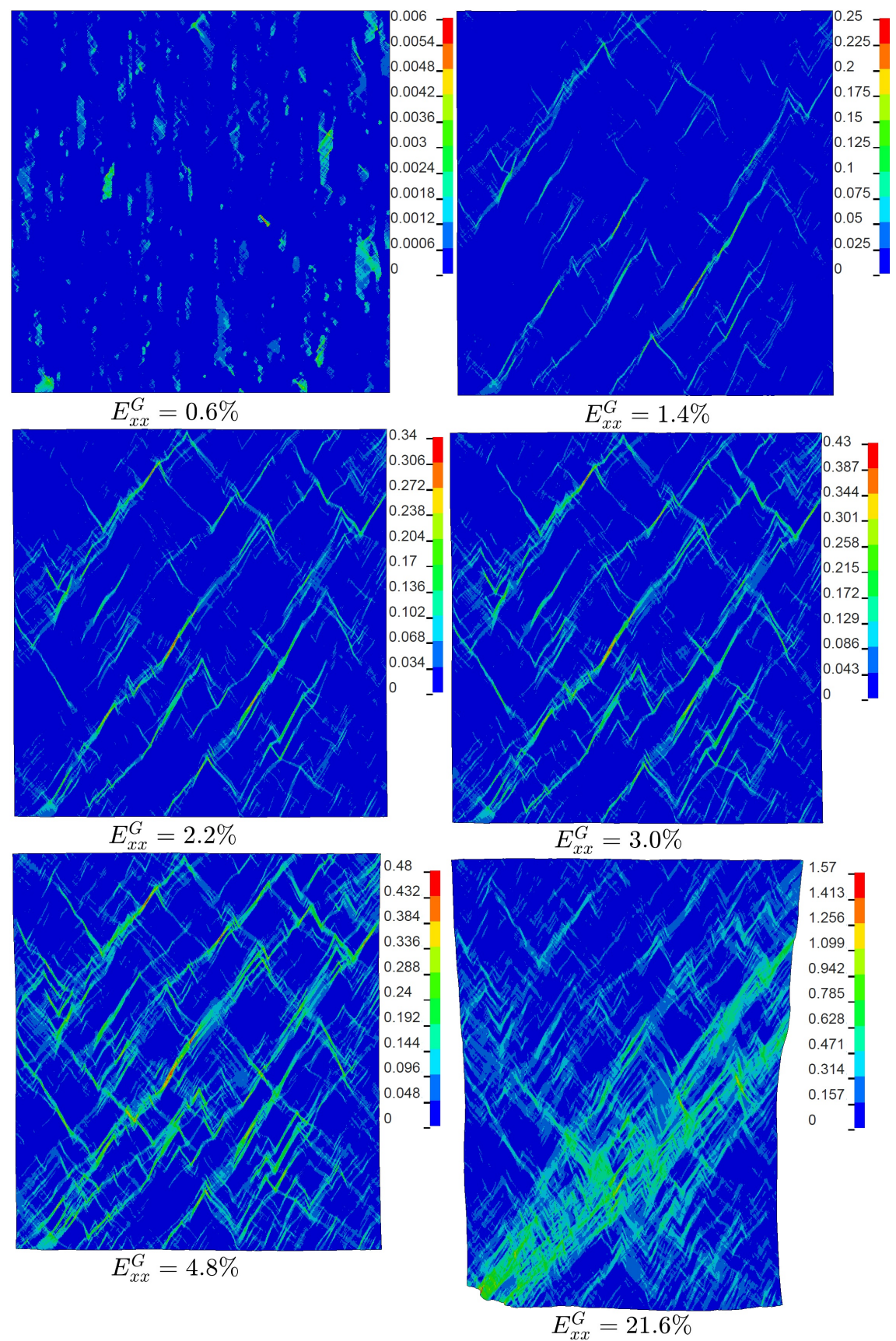

Figure 13: Contour plots of equivalent von Mises plastic strain obtained in the FE simulation at different levels of global Green-Lagrange strain $E_{x x}^{G}$ in the loading direction, corresponding approximately to the strain in the experiment and to the strain at which global shear bands formed in the simulation. The sheet thickness direction is horizontal, and the tensile force direction is vertical.

DOI: $10.1016 /$ j.ijplas.2021.103028 
The element size used in the simulation was $1 \mu \mathrm{m}$, while the size of the DIC elements used to measure displacement fields in the experiment was approximately 20 times larger. The plastic strains localised on the scale of some few elements when local shear bands formed. For better comparison with experimental data, the results of the simulations were processed to represent the same spatial resolution and strain measure as applied in the DIC analysis from which Figure 11 was obtained. The Green-Lagrange strain $E_{x x}$ was calculated for each element, and the average strain for $20 \times 20$ element patches was carried out. The results are shown in Figure 14 where the average value $\bar{E}_{x x}$ is plotted on the reduced nondeformed mesh for comparison purposes.

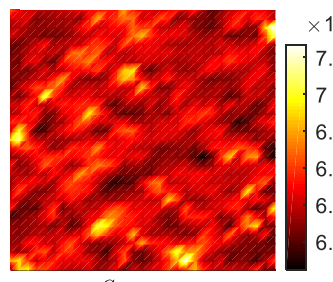

$E_{x x}^{G}=0.6 \%$

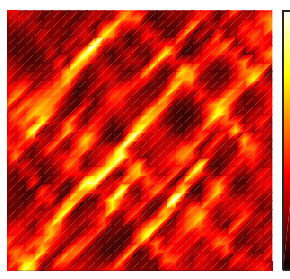

$E_{x x}^{G}=3.0 \%$

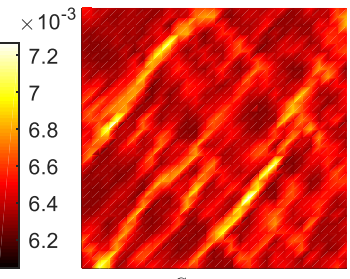

$E_{x x}^{G}=1.4 \%$

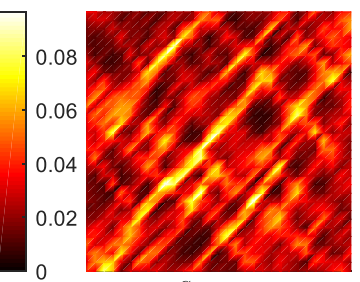

$E_{x x}^{G}=3.9 \%$

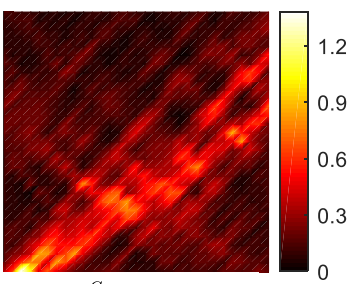

$E_{x x}^{G}=21.6 \%$

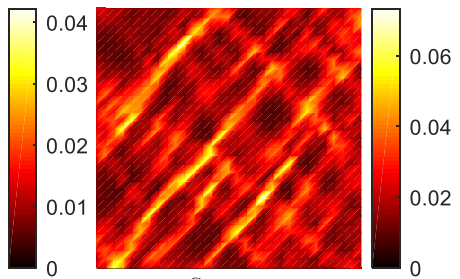

$E_{x x}^{G}=2.2 \%$

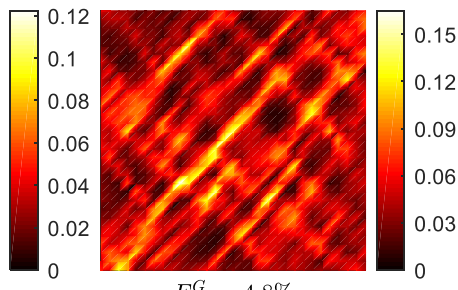

$E_{x x}^{G}=4.8 \%$

Figure 14: Fields of Green-Lagrange strain $\bar{E}_{x x}$ in the loading direction averaged over $20 \times$ 20 element patches from the FE simulation for selected global strain levels, corresponding approximately to the strain in the experiment and to the strain at which global shear bands formed in the simulation. The sheet thickness direction is horizontal, and the tensile force direction is vertical.

The averaged strain fields of the simulated polycrystal are similar to the experimentally measured fields. Both demonstrate initial transient strain patterns and early onset of smaller shear bands, thereby creating a more permanent strain pattern. The classical crystal plasticity model used in this study lacked 
intrinsic length scales (Shu and Fleck, 1999 Gurtin, 2000), i.e., the physical size of the grains and the distance to the grain boundaries in the simulation have no effect on the flow stress and work hardening. However, the size of the shear bands relative to the grain size in the simulation and the experiment was similar for the selected element size. In both cases, the bands passed through many grains in the length and width directions. This observation is illustrated for the CP-FEM simulation in Figure 15, where the average local strain field is plotted with overlaid grain boundaries for a global strain of $4.8 \%$.

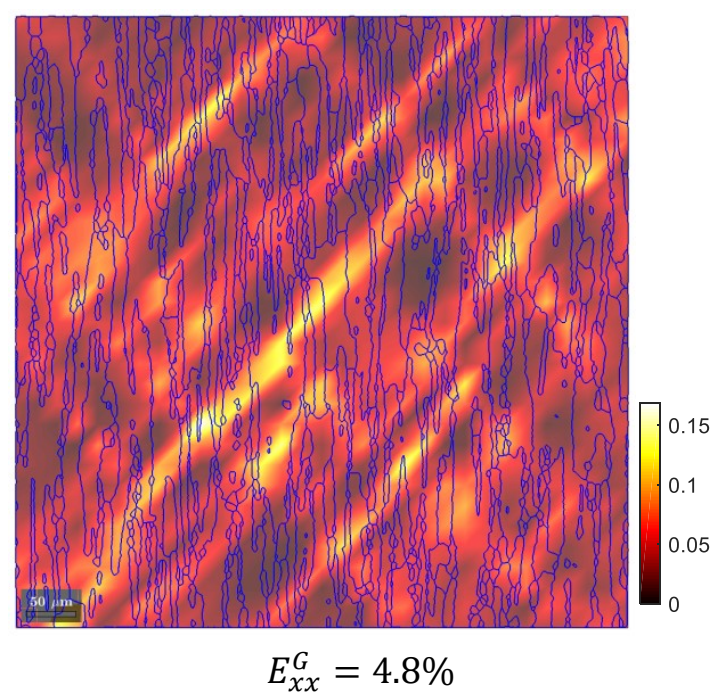

Figure 15: Fields of average Green-Lagrange strain $\bar{E}_{x x}$ in the loading direction for a global strain of $4.8 \%$, as obtained in the CP-FEM simulation with the grain boundaries overlaid. The sheet thickness direction is horizontal, and the tensile force direction is vertical.

The position of the strained bands at a global Green-Lagrange strain level of $2.2 \%$ is plotted over the grain orientation map in Figure 16 and over the von Mises stress contour plot in Figure 17 to further help the analysis. The two figures show a complex interplay between grain orientations and shapes in the band formation and propagation. The bands mostly initiate in the softer grains with orientation close to $\langle 111\rangle$, marked by violet colour in the pole figure. The von Mises stress in these grains is about $400 \mathrm{MPa}$. After initiating in these grains, the bands may propagate further, slightly or abruptly change direction, or become scattered. The bands are sometimes scattered by the grains with orientations close to $\langle 101\rangle$, marked by green colour (see a large grain in the very center for the most illustrative example), or stopped by harder grains with orientations between $\langle 111\rangle$ and $\langle 101\rangle$, marked by light blue colour. The levels of von Mises stress vary between $500-600 \mathrm{MPa}$ in the harder grains and 800$900 \mathrm{MPa}$ in the hardest grains, as can bee seen by comparing Figure 16 to Figure 17.

DOI: $10.1016 /$ j.ijplas.2021.103028 


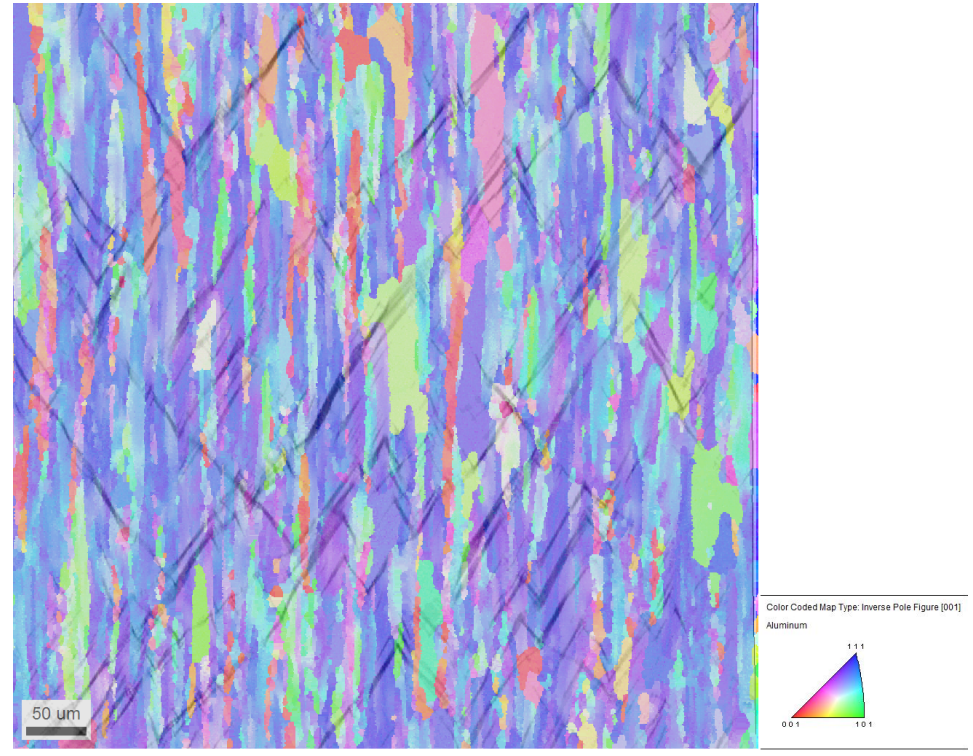

Figure 16: Equivalent plastic strain field showing the position of strained bands at $2.2 \%$ global strain on top of the grain orientation plot obtained by EBSD. The sheet thickness direction is horizontal and the tensile force direction is vertical. 

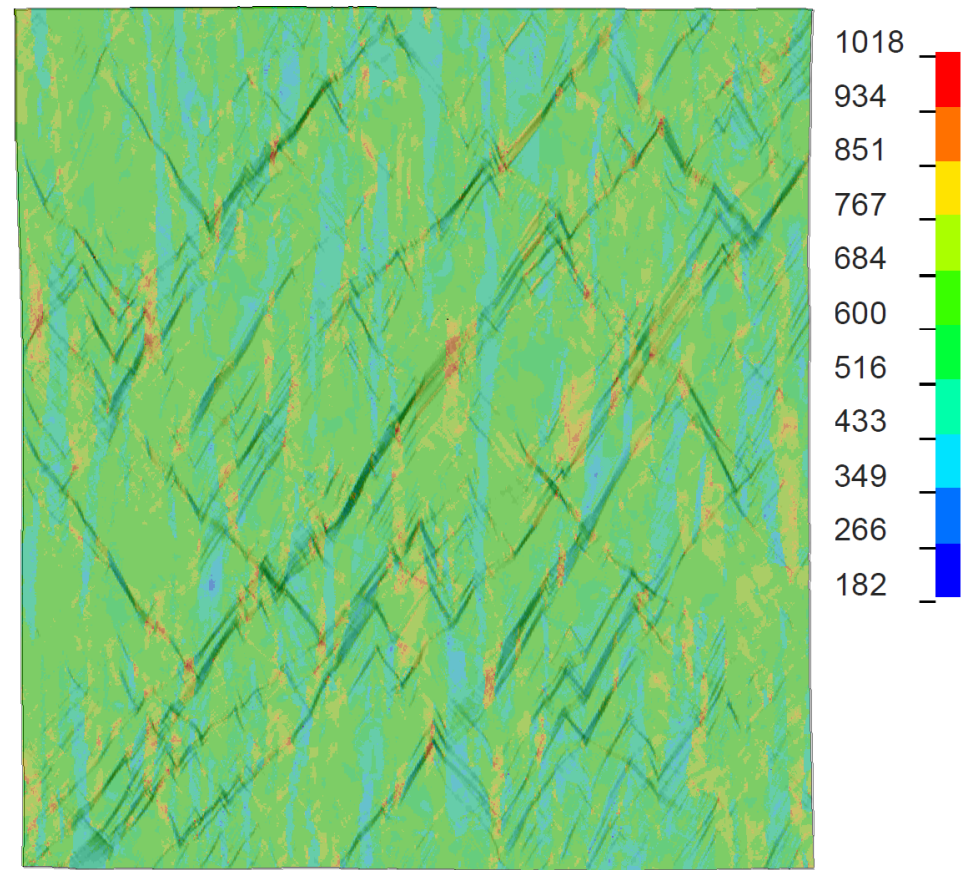

Figure 17: Equivalent plastic strain field showing the position of strained bands at $2.2 \%$ global strain on top of the von Mises stress contour plot in MPa. The sheet thickness direction is horizontal and the tensile force direction is vertical.

To quantitatively evaluate the distribution of strains in the simulation, profiles are shown in Figure 18 in the same manner as for the experiment (Figure 12). The strain profile along the line $\zeta_{2}$ is the most similar to the experimental strain profile - it crosses one of the major and two minor bands, while the profile $\zeta_{1}$ runs along one of the bands in the start and profile $\zeta_{3}$ runs along a minor band for its whole range. Correspondingly, for the profile $\zeta_{2}$ the peak strain is around $10 \%$ for the global strain of $4.8 \%$, compared to the peak strain of $7 \%$ for the global strain of $4.2 \%$ in the experimental profile in Figure 12 . The CP-FEM results were markedly closer to the experimental data than those obtained in a previous attempt at modelling the plane strain deformation of the notch tip with isotropic von Mises plasticity (Morgeneyer et al. 2014).

DOI: $10.1016 /$ j.ijplas.2021.103028 


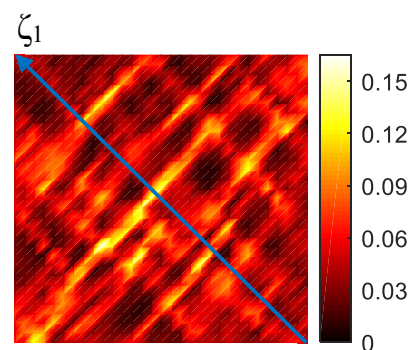

$E_{x x}^{G}=4.8 \%$

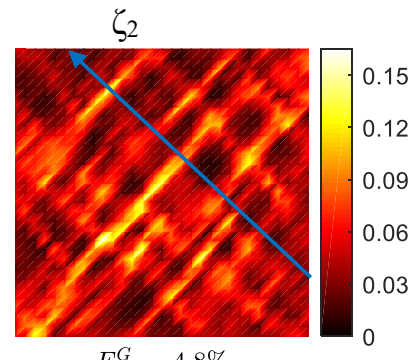

$E_{x x}^{G}=4.8 \%$
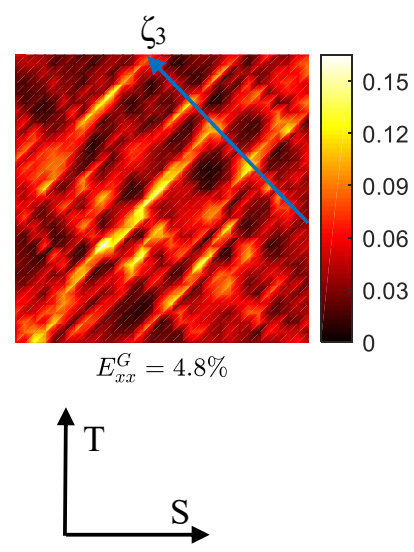
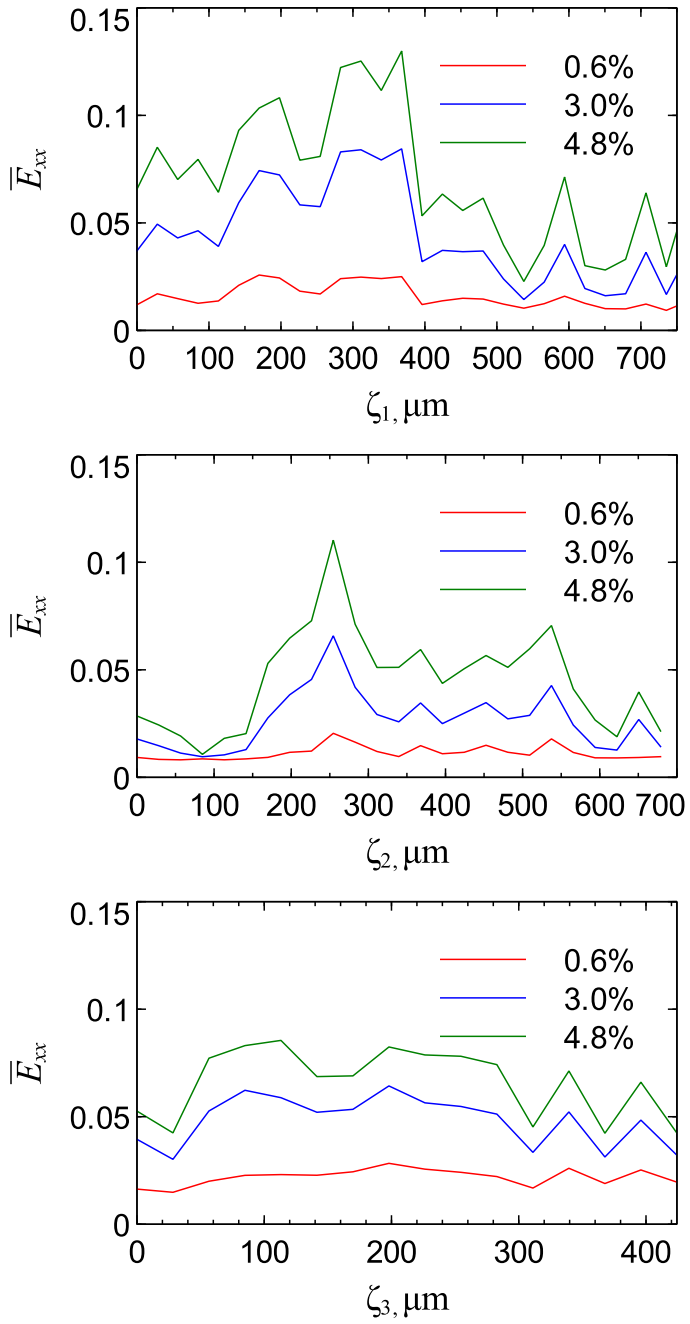

Figure 18: Simulated strain fields and profiles of averaged Green-Lagrange strain $\bar{E}_{x x}$ in the loading direction for a global level of $4.8 \%$. The profiles in the right figures are plotted along the slant line shown in the left plots, where $\zeta_{i}$ is the coordinate along the line.

DOI: $10.1016 /$ j.ijplas.2021.103028 
T.F. Morgeneyer et al., International Journal of Plasticity, 144 (2021) 103028

\section{Discussion}

The possible physical origins of slant strained bands ahead of the notch root in a thin sheet made of AA7075-T651 aluminium alloy were investigated in this study. These origins were investigated experimentally using laminography to monitor an in situ test and projection DIC, as an alternative to DVC, benefiting from the plane strain condition ahead of the notch root (i.e., with no strain in the crack propagation direction). Similar to the findings for other aluminium alloys of the 2XXX series (Morgeneyer et al., 2014, 2016; Buljac et al., 2018), slant strained bands ahead of the notch root were observed. These bands contained approximately twice as much strain as the surrounding material. During straining, the strain levels increased both in the bands and in the surrounding material, with no measurable damage development. At more elevated strain levels, some bands became more prevalent, and fracture eventually occurred along one of these bands. Potential origins of slant strained bands investigated in previous studies are summarised below:

- Soft zones were shown to cause slant strained bands in plane strain FE simulations with von Mises plasticity (Morgeneyer et al., 2016). However, the ratio of the strain within the bands to that outside was approximately 1.15 , which was far lower than in the experimental findings.

- Porous plasticity models failed to reproduce the early slant strained bands observed in experiments (Morgeneyer et al., 2014, 2016).

- Anisotropic plasticity models in conjunction with porous plasticity also failed to reproduce the slant strained bands (Morgeneyer et al., 2016).

- In aluminium alloys, strain rate bands may appear at the sample scale due to dynamic strain ageing (Ren et al., 2019). Accounting for PLC effects in models, slant strained bands could successfully be reproduced (Rousselier et al., 2017). However, the strained bands remained mobile in space in those simulations. In addition, the AA7075 alloy in the peak-aged condition (T651) is not known to exhibit PLC effects.

- Hahn and Rosenfield (Hahn and Rosenfield, 1965) suggested another possibility in which the plastic zone becomes first unstable and then ductile fracture (and crack extension) follows in the wake of instability.

In the present study, crystallographic effects on early strain heterogeneities were explored. Advantage was taken of the plane strain condition ahead of the notch root (with no strain in crack propagation direction) to perform 2D plane strain CP-FEM simulations using the measured grain orientation and the real grain shapes. With these input data, very fine slant strained bands could be observed very early in the simulation. When the spatial resolution of the FE analysis was decreased to that of DIC, patterns very similar to those observed experimentally were found, with strained bands that were motionless with respect to the microstructure and that covered tens of grains. The ratio of

DOI: $10.1016 /$ j.ijplas.2021.103028 
T.F. Morgeneyer et al., International Journal of Plasticity, 144 (2021) 103028

the strain inside and outside of the strained bands obtained by crystal plasticity simulations (CP-FEM) was close to that experimentally measured.

In the present work, the role of nucleated damage on micrometre-sized particles on strain heterogeneity, localisation and final fracture was not studied in detail. This is mainly due to the fact that experimentally, in the studied ROI $1 \mathrm{~mm}$ away from the notch root, no notable damage nucleation, growth and coalescence could be observed before final failure. Hard particles could be important for the initiation and development of shear bands, even for isotropic elastoplastic matrices (Gänser et al. 2000). The CP-FEM model was modified to investigate this possible effect. The size and area ratio of the particles were obtained from an experimental study on the same alloy (Jordon et al. 2009). The particles were introduced as approximately equiaxed (i.e., as closely as the structured mesh allowed) randomly distributed patches of elements with isotropic elastic behaviour and elastic constants corresponding to iron (Young's modulus $E=210 \mathrm{GPa}$, Poisson ratio $\nu=0.3$ ). A particle diameter of $9 \mu \mathrm{m}$ and an area ratio of 0.025 were adopted directly from (Jordon et al. 2009). Contour plots of the equivalent von Mises plastic strain for the modified and original CP-FEM models are presented in Figure 19. The results show that the particles have very little effect on the shear bands. They do not cause any changes in the emerging band pattern or intensity, and only arrest propagation of some bands. In addition, a simulation was performed with elastic particles in a von Mises material, using material properties that represent the average plastic behaviour of the alloy. The results show that, similarly to the results reported by Gänser et al. (2000), the heterogeneity introduced by particles may cause localisation, but requires much higher levels of global strain than what was observed experimentally.

DOI: $10.1016 /$ j.ijplas.2021.103028 

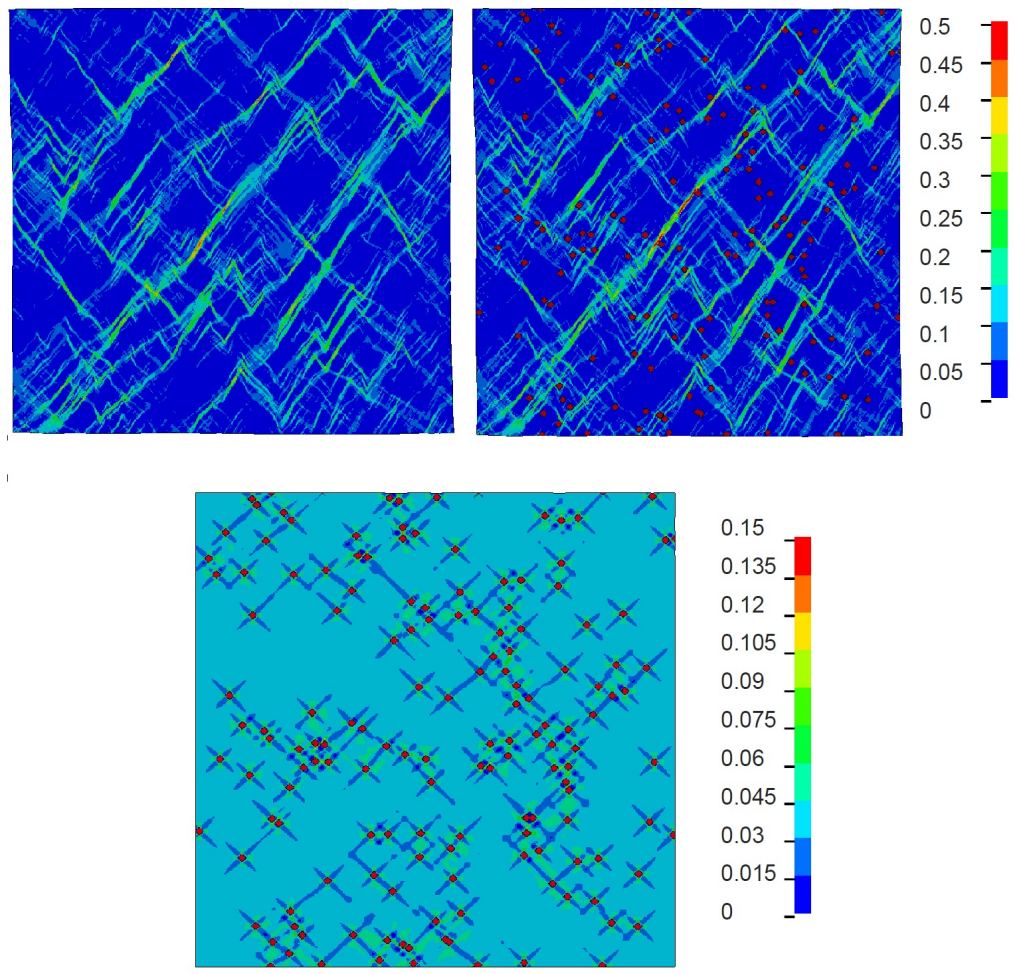

Figure 19: Contour plots of equivalent von Mises plastic strain obtained in an FE simulation at $4.7 \%$ global Green-Lagrange strain $E_{x x}^{G}$ in the loading direction for the original CP-FEM model (top left), a modified CP-FEM model with elastic particles (top right), and a von Mises matrix with elastic particles (bottom). The sheet thickness direction is horizontal and the tensile direction is vertical.

In this study, and other and similar previous studies, slant strained bands were found experimentally under plane strain conditions as precursors to localisation and fracture. A mixture of shear and tensile load is certainly present in these shear bands (Mahgoub et al., 2003). For an aluminium alloy containing initial porosity, voids have been found to rotate and elongate in slant strained bands (Ueda et al., 2014: Morgeneyer et al., 2016). The stress triaxility levels were identified to range between 0.4 and 1 in this location (Ueda et al., 2014). On the final failure surfaces of the slant bands mostly sub-micrometre-sized dimples were found (Morgeneyer et al., 2014; Ueda et al., 2014), whereas closer to the notch root, where the crack was oriented normal to the loading direction, large voids were found on the majority of the fracture surface.

There are some similarities between the failure mechanisms in the shear bands of AA2024 T3 subjected to shear (i.e., triaxiality close to zero) (TancogneDejean et al., 2020) and the mechanisms in slant strained bands during tearing. Void growth was limited, and rather void rotation and elongation was found. Final fracture occurred via sub-micrometre-sized voids having nucleated on dis-

DOI: $10.1016 /$ j.ijplas.2021.103028 
T.F. Morgeneyer et al., International Journal of Plasticity, 144 (2021) 103028

persoid particles. In other words, it seems that the proportion of large voids nucleated on micrometre-sized intermetallic particles, which may govern high stress triaxility failure (Petit et al., 2019), do not lead to substantial void growth in slant strained bands. The ductile damage scenario seems to include strain heterogeneity, mainly due to crystal plasticity effects, which precedes localisation. Damage may nucleate on micrometre-sized particles in the bands at later stages of deformation. However, void nucleation at a secondary sub-micrometre population of particles, such as dispersoids (Ueda et al., 2014, Tancogne-Dejean et al. 2020) and also intergranular failure (Pedersen et al., 2011), may cover the majority of the fracture surface.

The current simulations have some limitations, and there is still room for improvement. The microstructure used for creating the FE model (i.e., the set of crystallographic orientations) was measured on the same alloy but not exactly on the ROI in which projection DIC was performed, as EBSD would require a destructive uncovering of the surface. The area investigated with EBSD should be large enough to represent the same microstructure as in the experiment in terms of crystallographic texture and its variation throughout the material, the typical misorientations between the grains, and the grain size and shape. The area investigated with DIC in the experiment was a 3D structure lying in the vicinity of a notch in a specimen undergoing approximately a plane strain condition predominantly tensile in one direction. In the simulation, it was represented by a simplified 2D plane strain model. The effects of the surrounding 3D structure and boundary conditions were neglected. It would also be highly interesting to re-analyse the full specimen, or a large part of it around the notch in $3 \mathrm{D}$ to investigate the development of the crack from the beginning and the development of the plastic zone. This will require other computational means unless it is carried out for a material with a coarse microstructure.

The crystal plasticity model used in the analysis considered only plastic deformation by slip combined with a relatively simple work hardening rule to account for the effects of dislocation storage, dynamic recovery, and self- and latent hardening. The deformation and strain localisation in the specimen may be affected by a number of physical effects that were not modelled, such as those of grain boundaries, precipitation structure, and strain gradients (i.e., nonlocality).

Damage and softening effects of voids and crack propagation were not included in the model. The results should therefore be interpreted with care and in a qualitative sense. Conversely, the study used a more realistic and detailed microstructure model than many other studies (Taupin et al., 2016; Gupta et al. 2019). In the present case, the experiment on an alloy with pancake-shaped grains deforming with good approximation in plane strain conditions in the plane normal to the rolling direction made the use of a $2 \mathrm{D}$ model less of a simplification and more a reproduction of the real structure.

Despite its limitations, the crystal plasticity model was more successful at reproducing the strain patterns before fracture than macroscopic plasticity models. The heterogeneity of the material was introduced as a variation of the yield strength (Morgeneyer et al. 2016). When the crystal plasticity model was used,

DOI: $10.1016 /$ j.ijplas.2021.103028 
T.F. Morgeneyer et al., International Journal of Plasticity, 144 (2021) 103028

the heterogeneity of the material was induced by the misorientation of grains in a natural way, without relying on any additional assumption. The alloys with low work hardening and high yield stress demonstrate a propensity for localisation into shear bands in CP-FEM simulations (Khadyko et al. 2016) without the introduction of any imperfections or material softening features.

Strain localisation in FE models is mesh dependent in the sense that the minimal band width is limited by the element size, and at lower mesh resolutions, the bands may not form at all. Conversely, the band pattern (i.e., position and length) is not dependent on the mesh resolution as long as the resolution is sufficient to produce it, but depends on the modelled microstructure and material properties (Khadyko et al., 2016, Barbe et al. 2009 ). The convergence of the band pattern for the selected model was tested by producing and running simulations in which each of the $620 \times 620$ EBSD grid points was represented by $2 \times 2=4$ elements with the same orientation. The local strain levels in the bands were somewhat higher in the most deformed elements in the finer mesh, but the band pattern remained the same as for the model with $620 \times 620$ elements. The averaged local strain was also similar for both resolutions. The effect of mesh refinement on shear bands in CP-FEM simulations is well known and investigated thoroughly (Lim et al. 2019).

Both DIC and CP-FEM analyses showed similar orientations (about $45^{\circ}$ with respect to the tensile axis), width, and intensity in the strained bands when the CP-FEM results were mapped onto a coarser mesh, corresponding approximately to the DIC discretisation. The microstructure included a lot of smaller grains among the elongated larger crystals. The direction of strained bands was only slightly affected by passing through smaller grains and the boundaries of larger grains.

The aspect of the CP-FEM simulation that can most readily be improved is the single crystal plasticity model. It was shown that the latent hardening matrix has a strong influence on the local strain distribution (Khadyko et al., 2018). The effect of grain boundary slip compatibility was shown to strongly promote the formation of bands (Taupin et al. 2016). In that study, a very simplified rectangular structure was analysed, where the nonlocal material model was the main driver promoting strained bands. The realistic microstructure used in the present study produced shear bands even with a local single crystal plasticity model. As a possibility for future studies, a realistic large-scale structure could be combined with single-crystal plasticity models that include nonlocal effects (Taupin et al., 2016), dynamic strain ageing (Gupta et al., 2019), if appropriate, or damage due to void growth (Han et al. 2013), although the more advanced $\mathrm{CP}$ models require a large increase in computation time and significantly limit the resolution of the microstructure.

\section{Conclusion}

Crystallographic aspects of heterogeneous plastic flow during ductile tearing were assessed experimentally and numerically. 3D imaging of an in situ

DOI: $10.1016 /$ j.ijplas.2021.103028 
T.F. Morgeneyer et al., International Journal of Plasticity, 144 (2021) 103028

experiment was carried out using a flat and notched specimen made of AA7075T651 that showed strong plastic anisotropy. The region ahead of the notch root was imaged by synchrotron laminography at several load steps. One millimetre ahead of the notch root, there was no deformation in the crack propagation direction (i.e., a plane strain condition was found). Instead of using DVC for the strain field measurement inside the material, this plane strain condition was utilised to enhance image contrast by projecting intermetallic particles in a $100 \mu \mathrm{m}$ thick slice along the crack propagation direction (i.e., zero strain direction) onto a single 2D plane. Via subsequent 2D DIC using these projections of maximum grey level, displacement fields were measured in a fast and robust way as an alternative to DVC. Slant strained bands were found very early on, and these bands were shown to be stable in space. Final fracture occurred along one of the most prevalent bands. The ratio between the strain inside and outside this band was of the order of 2 to 3 .

CP-FEM simulations were carried out under the assumption of plane strain conditions using the grain shape and grain orientation of AA7075-T651. The spatial resolution of the FE simulation was adapted by averaging the strain fields in areas of $20 \times 20 \mathrm{\mu m}^{2}$ to be comparable to the projection DIC results. The predicted crystal plasticity strain fields led to the following conclusions:

- Slant strained bands were observed since the very beginning of the loading history.

- The bands remained stable in space and crossed the entire sample width, including dozens of grains.

- These bands were not localisation bands, as the strains also increased in the surrounding material. Rather, they were strain heterogeneities introduced by the microstructure.

In the region of interest, 50 to 100 grains were found over the thickness, suggesting that this is a situation where continuum mechanics material models such as von Mises plasticity are suited to describe the strain distribution. However, the current results showed experimentally a very heterogeneous strain distribution. The main trends of the heterogeneous strain distribution were captured by the 2D plane strain CP-FEM simulations, accounting for grain orientation and shape of the studied material. This result suggests that crystallographic effects play an important role in heterogeneous flow when hundreds of grains are involved. This heterogeneity was identified as the precursor to final localisation and slant fracture.

Similar studies with different microstructures in terms of grain shape, size, and texture are needed to further understand the effect of microstructure on early flow heterogeneity and final strain localisation during ductile forming and tearing, particularly in plane strain situations.

DOI: $10.1016 /$ j.ijplas.2021.103028 
T.F. Morgeneyer et al., International Journal of Plasticity, 144 (2021) 103028

Acknowledgements $\mathrm{ABu}, \mathrm{FH}, \mathrm{LH}, \mathrm{TFM}$ thank the French Agence Nationale de la Recherche (Cominside ANR-14-CE07-0034 and LAMBDA ANR-17CE08-0051 projects) for partial funding of this work. Xiang KONG is thanked for some help with the figures. $\mathrm{ABe}, \mathrm{OSH}$, and TB gratefully acknowledge the financial support from NTNU and the Research Council of Norway through the FRINATEK Programme, Project No. 250553 (FractAl). ESRF is thanked for beamtime mi1241.

DOI: $10.1016 /$ j.ijplas.2021.103028 
T.F. Morgeneyer et al., International Journal of Plasticity, 144 (2021) 103028

\section{References}

Badulescu, C., Grédiac, M., Haddadi, H., Mathias, J.D., Balandraud, X., Tran, H.S., 2011. Applying the grid method and infrared thermography to investigate plastic deformation in aluminium multicrystal. Mechanics of Materials $43,36-53$.

Bao, Y., Wierzbicki, T., 2004. On fracture locus in the equivalent strain and stress triaxiality space. International Journal of Mechanical Sciences 46, 81 98.

Barbe, F., Quey, R., Musienko, A., Cailletaud, G., 2009. Three-dimensional characterization of strain localization bands in high-resolution elastoplastic polycrystals. Mechanics Research Communications 36, 762-768.

Bay, B., Smith, T., Fyhrie, D., Saad, M., 1999. Digital volume correlation: three-dimensional strain mapping using X-ray tomography. Exp. Mech. 39, $217-226$.

Bornert, M., Chaix, J., Doumalin, P., Dupré, J., Fournel, T., Jeulin, D., Maire, E., Moreaud, M., Moulinec, H., 2004. Mesure tridimensionnelle de champs cinématiques par imagerie volumique pour l'analyse des matériaux et des structures. Inst. Mes. Métrol. 4, 43-88.

Bretheau, T., Crépin, J., Doumalin, P., Bornert, M., 2003. Microextensometry: a tool for the mechanics of materials. Rev. Met. Paris 5, 567-575.

Bron, F., Besson, J., 2006. Simulation of the ductile tearing for two grades of 2024 aluminum alloy thin sheets. Eng. Fract. Mech. 73, 1531-1552.

Buljac, A., Hild, F., Helfen, L., Morgeneyer, T., 2018. On deformation and damage micromechanisms in strong work hardening 2198 T3 aluminium alloy. Acta Mat. 149, 29-45.

Buljac, A., Taillandier-Thomas, T., Morgeneyer, T., Helfen, L., Roux, S., Hild, F., 2016. Slant strained band development during flat to slant crack transition in AA 2198 T8 sheet: in situ 3D measurements. Int. J. Fract. 200, 49-62.

Demir, E., Gutierrez-Urrutia, I., 2020. Investigation of strain hardening near grain boundaries of an aluminum oligocrystal: Experiments and crystal based finite element method. International Journal of Plasticity 136, 102898.

Dumoulin, S., Hopperstad, O.S., Berstad, T., 2009. Investigation of integration algorithms for rate-dependent crystal plasticity using explicit finite element codes. Computational Materials Science 46, 785-799.

Flanagan, D., Belytschko, T., 1981. A uniform strain hexahedron and quadrilateral with orthogonal hourglass control. International journal for numerical methods in engineering 17, 679-706.

DOI: 10.1016/j.ijplas.2021.103028 
T.F. Morgeneyer et al., International Journal of Plasticity, 144 (2021) 103028

Fourmeau, M., Børvik, T., Benallal, A., Hopperstad, O.S., 2013. Anisotropic failure modes of high-strength aluminium alloy under various stress states. International Journal of Plasticity 48, 34-53.

Fourmeau, M., Børvik, T., Benallal, A., Lademo, O.G., Hopperstad, O.S., 2011. On the plastic anisotropy of an aluminium alloy and its influence on constrained multiaxial flow. International Journal of Plasticity 27, 2005-2025.

Fourmeau, M., Marioara, C.D., Børvik, T., Benallal, A., Hopperstad, O.S., 2015. A study of the influence of precipitate free zones on the strain localization and failure of the aluminium alloy AA7075-T651. Philosophical Magazine 95, 3278-3304.

Ganesan, S., Yaghoobi, M., Githens, A., Chen, Z., Daly, S., Allison, J., Sundararaghavan, V., 2020. The effects of heat treatment on the response of WE43 Mg alloy: crystal plasticity finite element simulation and SEM-DIC experiment. International Journal of Plasticity , 102917.

Gänser, H.P., Werner, E.A., Fischer, F.D., 2000. Forming limit diagrams: a micromechanical approach. International journal of mechanical sciences 42 , 2041-2054.

Grujicic, M., Batchu, S., 2002. Crystal plasticity analysis of earing in deepdrawn ofhc copper cups. Journal of materials science 37, 753-764.

Guery, A., Latourte, F., Hild, F., Roux, S., 2014. Characterization of SEM speckle pattern marking and imaging distortion by Digital Image Correlation. Measurement Science and Technology 25, 015401.

Gupta, S., Taupin, V., Fressengeas, C., Chevy, J., 2019. Crystal plasticity modeling of the effects of crystal orientation and grain-to-grain interactions on DSA-induced strain localization in Al-Li alloys. Materialia 8, 100467.

Gurtin, M.E., 2000. On the plasticity of single crystals: free energy, microforces, plastic-strain gradients. Journal of the Mechanics and Physics of Solids 48, 989-1036.

Hahn, G.T., Rosenfield, A.R., 1965. Local yielding and extension of a crack under plane stress. Acta Metallurgica 13, 293-306.

Hallquist, J.O., et al., 2006. Ls-dyna theory manual. Livermore software Technology corporation $3,25-31$.

Han, X., Besson, J., Forest, S., Tanguy, B., Bugat, S., 2013. A yield function for single crystals containing voids. International Journal of Solids and Structures $50,2115-2131$.

Helfen, L., Baumbach, T., Mikulík, P., Kiel, D., Pernot, P., Cloetens, P., Baruchel, J., 2005. High-resolution three-dimensional imaging of flat objects by synchrotron-radiation computed laminography. Appl. Phys. Lett. 86, 071915 .

DOI: $10.1016 /$ j.ijplas.2021.103028 
T.F. Morgeneyer et al., International Journal of Plasticity, 144 (2021) 103028

Heripre, E., Dexet, M., Crepin, J., Gélebart, L., Roos, A., Bornert, M., Caldemaison, D., 2007. Coupling between experimental measurements and polycrystal finite element calculations for micromechanical study of metallic materials. International Journal of Plasticity 23, 1512-1539.

Hild, F., Bouterf, A., Roux, S., 2015. Damage Measurements via DIC. International Journal of Fracture 191, 77-105.

Jordon, J., Horstemeyer, M., Solanki, K., Bernard, J., Berry, J., Williams, T., 2009. Damage characterization and modeling of a 7075-T651 aluminum plate. Materials Science and Engineering: A 527, 169-178.

Kapoor, K., Yoo, Y.S.J., Book, T.A., Kacher, J.P., Sangid, M.D., 2018. Incorporating grain-level residual stresses and validating a crystal plasticity model of a two-phase Ti-6Al-4 V alloy produced via additive manufacturing. Journal of the Mechanics and Physics of Solids 121, 447-462.

Khadyko, M., Dumoulin, S., Børvik, T., Hopperstad, O.S., 2015. Simulation of large-strain behaviour of aluminium alloy under tensile loading using anisotropic plasticity models. Computers \& Structures 157, 60-75.

Khadyko, M., Dumoulin, S., Hopperstad, O.S., 2016. Texture gradients and strain localisation in extruded aluminium profile. International Journal of Solids and structures 97, 239-255.

Khadyko, M., Marioara, C.D., Dumoulin, S., Børvik, T., Hopperstad, O.S., 2017. Effects of heat-treatment on the plastic anisotropy of extruded aluminium alloy AA6063. Materials Science and Engineering: A 708, 208-221.

Khadyko, M., Sturdy, J., Dumoulin, S., Hellevik, L.R., Hopperstad, O.S., 2018. Uncertainty quantification and sensitivity analysis of material parameters in crystal plasticity finite element models. Journal of Mechanics of Materials and Structures 13, 379-400.

Landron, C., Maire, E., Adrien, J., Suhonen, H., Cloetens, P., Bouaziz, O., 2012. Non-destructive 3-D reconstruction of the martensitic phase in a dual-phase steel using synchrotron holotomography. Scripta Mat. 66, 1077-1080.

Lim, H., Battaile, C.C., Bishop, J.E., Foulk III, J.W., 2019. Investigating mesh sensitivity and polycrystalline rves in crystal plasticity finite element simulations. International Journal of Plasticity 121, 101-115.

Lim, H., Carroll, J., Battaile, C.C., Buchheit, T., Boyce, B., Weinberger, C., 2014. Grain-scale experimental validation of crystal plasticity finite element simulations of tantalum oligocrystals. International Journal of Plasticity 60, $1-18$.

Lim, H., Dingreville, R., Deibler, L.A., Buchheit, T.E., Battaile, C.C., 2016. Investigation of grain-scale microstructural variability in tantalum using crystal plasticity-finite element simulations. Computational Materials Science 117, 437-444.

DOI: $10.1016 /$ j.ijplas.2021.103028 
T.F. Morgeneyer et al., International Journal of Plasticity, 144 (2021) 103028

Lin, F., Shi, Q., Delannay, L., 2020. Microscopic heterogeneity of plastic strain and lattice rotation in partially recrystallized copper polycrystals. International Journal of Solids and Structures 184, 167-177.

Lugo, M., Jordon, J.B., Tschopp, M.A., Horstemeyer, M., Gokhale, A., 2011. Quantification of Damage Evolution in a 7075 Aluminum Alloy Using an Acoustic Emission Technique. Mat. Sci. Eng. A528, 6708-6714.

Mahgoub, E., Deng, X., Sutton, M., 2003. Three dimensional stress and deformation fields around flat and slant cracks under remote mode I loading conditions. Eng. Fract. Mech. 70, 2527-2542.

Mainprice, D., Hielscher, R., Schaeben, H., 2011. Calculating anisotropic physical properties from texture data using the mtex open-source package. Geological Society, London, Special Publications 360, 175-192.

Maire, E., Buffière, J., Salvo, L., Blandin, J., Ludwig, W., Létang, J., 2001. On the application of x-ray microtomography in the field of materials science. Adv. Eng. Mat. 3, 539-546.

Maire, E., Withers, P.J., 2014. Quantitative X-ray tomography. Int. Mat. Rev. $59,1-43$.

Mánik, T., Holmedal, B., 2014. Review of the taylor ambiguity and the relationship between rate-independent and rate-dependent full-constraints taylor models. International Journal of Plasticity 55, 152-181.

Morgeneyer, T., Taillandier-Thomas, T., Buljac, A., Helfen, L., Hild, F., 2016. On strain and damage interactions during tearing: 3D in situ measurements and simulations for a ductile alloy (AA2139-T3). J. Mech. Phys. Solids 96, $550-571$.

Morgeneyer, T., Taillandier-Thomas, T., Helfen, L., Baumbach, T., Sinclair, I., Roux, S., Hild, F., 2014. In situ 3D observation of early strain localisation during failure of thin $\mathrm{Al}$ alloy (2198) sheet. Acta Mat. 69, 78-91.

Myagotin, A., Voropaev, A., Helfen, L., Hänschke, D., Baumbach, T., 2013. Efficient Volume Reconstruction for Parallel-Beam Computed Laminography by Filtered Backprojection on Multi-Core Clusters. IEEE Trans. Image Process. $22,5348-5361$.

Park, N., Stoughton, T.B., Yoon, J.W., 2020. A new approach for fracture prediction considering general anisotropy of metal sheets. International Journal of Plasticity 124, $199-225$.

Pedersen, K.O., Børvik, T., Hopperstad, O.S., 2011. Fracture mechanisms of aluminium alloy AA7075-T651 under various loading conditions. Materials and Design 32, 97-107.

DOI: $10.1016 /$ j.ijplas.2021.103028 
T.F. Morgeneyer et al., International Journal of Plasticity, 144 (2021) 103028

Petit, T., Besson, J., Ritter, C., Colas, K., Helfen, L., Morgeneyer, T.F., 2019. Effect of hardening on toughness captured by stress-based damage nucleation in 6061 aluminum alloy. Acta Materialia 180, 349-365.

Petit, T., Ritter, C., Besson, J., Morgeneyer, T.F., 2018. Impact of machine stiffness on 'pop-in' crack propagation instabilities. Engineering Fracture Mechanics 202, 405-422.

Pineau, A., Benzerga, A., Pardoen, T., 2016. Failure of metals i: Brittle and ductile fracture. Acta Materialia 107, $424-483$.

Pinna, C., Lan, Y., Kiu, M., Efthymiadis, P., Lopez-Pedrosa, M., Farrugia, D., 2015. Assessment of crystal plasticity finite element simulations of the hot deformation of metals from local strain and orientation measurements. International Journal of Plasticity 73, 24-38.

Proudhon, H., Pelerin, M., King, A., Ludwig, W., 2020. In situ 4D mechanical testing of structural materials: The data challenge. Current Opinion in Solid State and Materials Science 24, 100834.

Ren, S.C., Morgeneyer, T.F., Mazière, M., Forest, S., Rousselier, G., 2019. Portevin-Le Chatelier effect triggered by complex loading paths in an $\mathrm{Al}-\mathrm{Cu}$ aluminium alloy. Philosophical Magazine 99, 659-678.

Rosenfield, A., Dai, P.K., Hahn, G.T., 1966. Crack extension and propagation under plane stress. Ship Structure Committee, SSC- 172 Report,U. S. Coast Guard Headquarters, Washington, D. C. 20226 .

Roth, C.C., Morgeneyer, T.F., Cheng, Y., Helfen, L., Mohr, D., 2018. Ductile damage mechanism under shear-dominated loading: In-situ tomography experiments on dual phase steel and localization analysis. International Journal of Plasticity 109, 169-192.

Rousselier, G., Morgeneyer, T.F., Ren, S., Mazière, M., Forest, S., 2017. Interaction of the Portevin-le Chatelier phenomenon with ductile fracture of a thin aluminum CT specimen: experiments and simulations. International Journal of Fracture 206, 95-122.

Rudnicki, J., Rice, J., 1975. Conditions for localization of deformation in pressure-sensitive dilatant materials. J. Mech. Phys. Solids 23, 371-394.

Saai, A., Louche, H., Tabourot, L., Chang, H., 2010. Experimental and numerical study of the thermo-mechanical behavior of al bi-crystal in tension using full field measurements and micromechanical modeling. Mechanics of Materials 42, 275-292.

Sachtleber, M., Zhao, Z., Raabe, D., 2002. Experimental investigation of plastic grain interaction. Materials Science and Engineering: A 336, 81-87.

DOI: $10.1016 /$ j.ijplas.2021.103028 
T.F. Morgeneyer et al., International Journal of Plasticity, 144 (2021) 103028

Shu, J.Y., Fleck, N.A., 1999. Strain gradient crystal plasticity: size-dependent deformation of bicrystals. Journal of the Mechanics and Physics of Solids 47, $297-324$.

St-Pierre, L., Héripré, E., Dexet, M., Crépin, J., Bertolino, G., Bilger, N., 2008. 3d simulations of microstructure and comparison with experimental microstructure coming from oim analysis. International Journal of Plasticity $24,1516-1532$.

Stander, N., Roux, W., Goel, T., Eggleston, T., Craig, K., 2008. Ls-opt user's manual. Livermore software technology corporation .

Sutton, M., 2013. Computer vision-based, noncontacting deformation measurements in mechanics: A generational transformation. Appl. Mech. Rev. 65, 050802 .

Sutton, M.A., Li, N., Joy, D., Reynolds, A.P., Li, X., 2007. Scanning Electron Microscopy for Quantitative Small and Large Deformation Measurements Part I: SEM Imaging at Magnifications from 200 to 10,000. Experimental Mechanics 47, 775-787.

Tancogne-Dejean, T., Roth, C.C., Morgeneyer, T.F., Helfen, L., Mohr, D., 2020. Ductile Damage of AA2024-T3 under Shear Loading: Mechanism Analysis Through In-Situ Laminography. Acta Materialia, 116556.

Taupin, V., Chevy, J., Fressengeas, C., 2016. Effects of grain-to-grain interactions on shear strain localization in Al-Cu-Li alloys. Int. J. Sol. Struct. 99, $71-81$.

Tekkaya, A., Bouchard, P.O., Bruschi, S., Tasan, C., 2020. Damage in metal forming. CIRP Annals 69, $600-623$.

Tomicevic, Z., Hild, F., Roux, S., 2013. Mechanics-aided digital image correlation. J. Strain Analysis 48, 330-343.

Torki, M.E., Benzerga, A.A., 2018. A mechanism of failure in shear bands. Extreme Mechanics Letters 23, 67 - 71 .

Ueda, T., Helfen, L., Morgeneyer, T., 2014. In situ laminography study of three-dimensional individual void shape evolution at crack initiation and comparison with Gurson-Tvergaard-Needleman-type simulations. Acta Mat. 78, $254-270$.

Vogelgesang, M., Farago, T., Morgeneyer, T.F., Helfen, L., dos Santos Rolo, T., Myagotin, A., Baumbach, T., 2016. Real-time image content based beamline control for smart 4D X-ray imaging. Journal of Synchrotron Radiation 23, $1254-1263$.

Zerbst, U., Heinimann, M., Dalle Donne, C., Steglich, D., 2009. Fracture and damage mechanics modelling of thin-walled structures. An overview. Eng. Fract. Mech. 76, 5-43.

DOI: $10.1016 /$ j.ijplas.2021.103028 
T.F. Morgeneyer et al., International Journal of Plasticity, 144 (2021) 103028

Zhang, C., Li, H., Eisenlohr, P., Liu, W., Boehlert, C., Crimp, M., Bieler, T., 2015. Effect of realistic 3D microstructure in crystal plasticity finite element analysis of polycrystalline Ti-5Al-2.5 Sn. International Journal of Plasticity $69,21-35$.

Zhu, G., Hu, X., Kang, J., Mishra, R.K., Wilkinson, D.S., 2011. Deformation inhomogeneity in large-grained AA5754 sheets. Materials Science and Engineering: A 528, 4187-4198.

DOI: $10.1016 /$ j.ijplas.2021.103028 